OPEN ACCESS

Edited by:

Iker Aranjuelo,

Universidad Pública de Navarra

(CSIS), Spain

Reviewed by:

Rafael Ribeiro,

Universidade Estadual de Campinas,

Brazil

Iris Finkemeier,

Max Planck Institute for Plant Breeding Research (MPG), Germany

${ }^{*}$ Correspondence:

Juan A. Perdomo

alejandro.perdomo@rothamsted.ac.uk

Specialty section:

This article was submitted to

Plant Physiology,

a section of the journal

Frontiers in Plant Science

Received: 07 November 2016

Accepted: 21 March 2017

Published: 13 April 2017

Citation:

Perdomo JA, Capó-Bauçà S, Carmo-Silva E and Galmés J (2017)

Rubisco and Rubisco Activase Play an Important Role in the Biochemical Limitations of Photosynthesis in Rice, Wheat, and Maize under High

Temperature and Water Deficit.

Front. Plant Sci. 8:490.

doi: 10.3389/fpls.2017.00490

\section{Rubisco and Rubisco Activase Play an Important Role in the Biochemical Limitations of Photosynthesis in Rice, Wheat, and Maize under High Temperature and Water Deficit}

\author{
Juan A. Perdomo ${ }^{1 *}$, Sebastià Capó-Bauçà², Elizabete Carmo-Silva ${ }^{3}$ and Jeroni Galmés² \\ ${ }^{1}$ Plant Biology and Crop Science, Rothamsted Research (BBSRC), Harpenden, UK, ${ }^{2}$ Research Group on Plant Biology \\ under Mediterranean Conditions, Universitat de les Illes Balears-INAGEA, Palma de Mallorca, Spain, ${ }^{3}$ Lancaster \\ Environment Centre, Lancaster University, Lancaster, UK
}

To understand the effect of heat and drought on three major cereal crops, the physiological and biochemical (i.e., metabolic) factors affecting photosynthesis were examined in rice, wheat, and maize plants grown under long-term water deficit (WD), high temperature $(H T)$ and the combination of both stresses (HT-WD). Diffusional limitations to photosynthesis prevailed under WD for the $\mathrm{C}_{3}$ species, rice and wheat. Conversely, biochemical limitations prevailed under WD for the $\mathrm{C}_{4}$ species, maize, under HT for all three species, and under HT-WD in rice and maize. These biochemical limitations to photosynthesis were associated with Rubisco activity that was highly impaired at HT and under HT-WD in the three species. Decreases in Rubisco activation were unrelated to the amount of Rubisco and Rubisco activase (Rca), but were probably caused by inhibition of Rca activity, as suggested by the mutual decrease and positive correlation between Rubisco activation state and the rate of electron transport. Decreased Rubisco activation at HT was associated with biochemical limitation of net $\mathrm{CO}_{2}$ assimilation rate $\left(A_{\mathrm{N}}\right)$. Overall, the results highlight the importance of Rubisco as a target for improving the photosynthetic performance of these $\mathrm{C}_{3}$ (wheat and rice) and $\mathrm{C}_{4}$ (maize) cereal crops under increasingly variable and warmer climates.

Keywords: crops, photosynthesis, Rubisco, Rubisco activase, temperature, water deficit

\section{INTRODUCTION}

As a consequence of climate change, global temperatures have increased over the last few decades and this warming trend is predicted to accelerate in the near future (IPCC, 2013). Increases in global temperatures are often accompanied by alterations in precipitation patterns, with effects on the amount, intensity, frequency and type of precipitation (Dore, 2005). The changing global climate is expected to have a detrimental effect on agriculture by increasing the prevalence of abiotic stresses.

Heat and drought are the principal abiotic stresses limiting plant growth and crop productivity. Photosynthesis, the main physiological process driving plant growth, is highly sensitive to drought and heat stress (Chaves et al., 2009; Mathur et al., 2014; Singh et al., 2014), especially 
when both stresses are imposed together (Carmo-Silva et al., 2012; Vile et al., 2012; Perdomo et al., 2015). Photosynthetic $\mathrm{CO}_{2}$ assimilation can be constrained by diffusive and biochemical limitations (Flexas and Medrano, 2002a; Pinheiro and Chaves, 2011). The diffusive limitations are a consequence of stomatal closure (i.e., decreased stomatal conductance, $g_{\mathrm{s}}$ ) and increased leaf resistance to $\mathrm{CO}_{2}$ transport from the atmosphere to the site of carboxylation (i.e., decreased mesophyll conductance, $g_{\mathrm{m}}$ ), as generally observed under mild to moderate water deficit (WD) (Chaves et al., 2003, 2009; Flexas et al., 2004; von Caemmerer and Evans, 2010).

The biochemical or metabolic components that limit photosynthesis under WD are less well described than the diffusion limitations (Galmés et al., 2007b). Metabolic limitations to photosynthesis under drought have been associated with impaired ATP synthesis (Tezara et al., 1999; Flexas et al., 2004; Singh et al., 2014), which is due to a decrease in the electron transport rate (J) (Flexas et al., 1999; Galmés et al., 2007a). Lower ATP availability, in turn, affects ribulose-1,5-bisphosphate $(\mathrm{RuBP})$ regeneration, thus limiting the rate of $\mathrm{CO}_{2}$ fixation. The effects of drought stress on Rubisco vary depending on the plant species and intensity of stress; some studies reported a dramatic reduction in Rubisco activity (Parry et al., 2002; Zhou et al., 2007) while others showed little or no inhibition of the enzyme (Panković et al., 1999; Pelloux et al., 2001). A meta-analyses suggested that Rubisco did not limit photosynthesis until severe or long-term drought stress was encountered (Flexas et al., 2006a). More recently, Galmés et al. (2011) suggested that low chloroplastic $\mathrm{CO}_{2}$ concentration $\left(C_{\mathrm{c}}\right)$ occurring under WD could induce de-activation of Rubisco in some Mediterranean species.

High leaf temperatures affect both electron transport capacity $\left(J_{\max }\right)$ and the maximum rate of carboxylation of Rubisco $\left(V_{\mathrm{cmax}}\right)$ (Dreyer et al., 2001; Yamori et al., 2006, 2008). On the contrary, data in literature suggest that high temperatures (HTs) do not sufficiently impair $g_{\mathrm{s}}$ and $g_{\mathrm{m}}$ to cause diffusion components to significantly limit photosynthesis (Bernacchi et al., 2002; Evans and von Caemmerer, 2013; Walker et al., 2013; von Caemmerer and Evans, 2015). Moderately HTs impair the activation of Rubisco by its catalytic chaperone, Rubisco activase (Rca), which becomes the primary cause of the decrease in photosynthesis in response to elevated temperature (Crafts-Brandner and Salvucci, 2000; Salvucci and Crafts-Brandner, 2004; Kim and Portis, 2005; Galmés et al., 2013). In addition to Rubisco activation, moderately HTs can also inhibit electron transport activity, ATP synthesis, and RuBP regeneration (Schrader et al., 2004; Yamori et al., 2008; Carmo-Silva and Salvucci, 2011). As the temperature increases further above the thermal optimum and reaches nonphysiological conditions, photosynthesis may be increasingly limited due to impairment of the physical integrity of electron transport components of the photosynthetic apparatus (Salvucci and Crafts-Brandner, 2004).

The above described effects of HT on the photosynthetic processes are mainly based on studies where measurements were done at HT in plants grown at a moderate (control) temperature. Although there is abundant evidence that photosynthesis can acclimate to temperature (Gunderson et al., 2000; Way and Yamori, 2014; Yamori et al., 2014), little is known about the effects of high growth temperature on the relative contribution of diffusive and biochemical limitations to photosynthesis. If biochemical limitations prevailing at HTs of measurement also predominate at HTs of growth, the analysis of Rubisco and Rca performance and thermal acclimation may provide valuable information toward the improvement of crop photosynthesis at HTs.

The activity of Rubisco is regulated by Rca, which facilitates the dissociation of inhibitory sugar phosphates from the active site of Rubisco in an ATP-dependent manner (Spreitzer and Salvucci, 2002). Most species studied to date, including rice and wheat, contain two isoforms of Rca, a shorter redoxinsensitive $\beta$-isoform of $41-43 \mathrm{kDa}$ and a longer redox-sensitive $\alpha$-isoform of $46-48 \mathrm{kDa}$ (Zhang and Portis, 1999). Some species, such as maize and tobacco, however, do not appear to contain significant amounts of the longer redox-sensitive $\alpha$-isoform (e.g., Salvucci et al., 1987). Changes in the redox status and $\mathrm{ADP} / \mathrm{ATP}$ ratio of the chloroplast modulate the activity of Rca, thereby mediating the regulation of Rubisco activation and net $\mathrm{CO}_{2}$ assimilation in response to the prevailing irradiance (Salvucci et al., 1985; Mott and Woodrow, 2000; Carmo-Silva and Salvucci, 2013; Scales et al., 2014). The activity of Rca is extremely thermally sensitive. This enzyme becomes inactive, decreasing the rate of net $\mathrm{CO}_{2}$ assimilation at moderately HTs.

The objective of the present study was to test the hypothesis that decreased Rubisco activation state limits photosynthesis under heat stress, and heat stress combined with WD, in the $\mathrm{C}_{3}$ cereals rice and wheat and the $\mathrm{C}_{4}$ cereal maize. The effects of long-term plant growth under WD, HT and the combination of both (HT-WD) were therefore investigated on Rubisco activity and amount, Rubisco activase content and Rubisco activation state and to relate them with the relative contributions of biochemical and diffusive limitations to photosynthesis in rice, wheat and maize.

\section{MATERIALS AND METHODS}

\section{Plant Material, Growth Conditions, and Treatments}

Rice (Oryza sativa L. cv. Bomba), wheat (Triticum aestivum L. cv. Cajeme) and maize (Zea mays L. cv. Carella) plants were grown from seeds in a greenhouse in $3.5 \mathrm{~L}$ pots containing a 70:30 mixture (v:v) of horticultural substrate $(60 \%$ Fine blonde peat, $40 \%$ Fine black peat, granulometry $0-10 \mathrm{~mm}, 3.5 \mathrm{~kg} / \mathrm{m}^{3}$ calcium dolomite and $1.12 \%$ of $\mathrm{N}-0.2 \%$ of $\mathrm{P}_{2} \mathrm{O}_{5}-0.2 \%$ of $\mathrm{K}_{2} \mathrm{O}$ plus $1.45 \%$ of microelements; Prohumin 6040, Projar S.A, Spain) and perlite (granulometry A13, Projar S.A, Spain). After 2 weeks, the seedlings were selected to uniform size with 1 plant per pot in maize, and 10 plants per pot in wheat and rice. Thereafter, the plants were moved to a controlled environment room. Light was provided by metal halide lamps (OSRAM, Germany) placed at specific distances from the plants to obtain a photosynthetically active photon flux density (PPFD) of $500 \mu \mathrm{mol} \mathrm{m}{ }^{-2} \mathrm{~s}^{-1}$, with a photoperiod of $12 \mathrm{~h}$ day/12 $\mathrm{h}$ night. The ambient temperature and the relative humidity were monitored with portable sensors 
Testo $175-\mathrm{H} 1$ data logger (Gerilab, Spain). The relative humidity was maintained between 40 and $60 \%$ using humidifiers.

For logistical reasons, the plants were grown in two sets, which were subjected to each of the two temperature treatments. A first set of plants of the three species was grown at the control temperature (Control, $25 / 20^{\circ} \mathrm{C}$; VPD, $1.8 / 1.0 \mathrm{kPa}$ day/night); and a second set of plants was grown at HT (38/33 ${ }^{\circ} \mathrm{C}$; VPD, 3.5/2.3 kPa day/night). Only temperature and VPD differed between the two sets of plants or experiments, while all other environmental conditions (e.g., light intensity and quality, air removal, photoperiod duration) were identical and computer-controlled.

For each set of plants, i.e., for each growing temperature and VPD treatment, ten pots per species were grown at soil field capacity until plants had developed fully expanded leaves (typically 2 weeks). Thereafter, 20 days after germination, pots of all species were randomly assigned to two different irrigation treatments: five pots per species were maintained at $100 \%$ field capacity during the whole experiment (well-watered treatment, WW) and the other five pots were maintained at $45 \%$ field capacity (moderate WD treatment, WD), as determined by pot weighing every day and compensating the daily water losses with 50\% Hoagland's solution that provided all necessary nutrients for the plant. The soil water availability for plants under WD was determined with respect to the control by measuring the water weight in five representative samples of the substrate mixture used in the experiment. Plants were considered to be under WD when $g_{\mathrm{s}}$ was decreased by $40 \%$ compared to the well-watered plants; $g_{s}$ was considered as a good indicator of the WD status, as previously demonstrated (Medrano et al., 2002). Therefore, a total of four treatments were established: $25^{\circ} \mathrm{C}$ of growth temperature and well-watered (control), $25^{\circ} \mathrm{C}$ of growth temperature and $\mathrm{WD}, 38^{\circ} \mathrm{C}$ of growth temperature and well-watered (HT) and $38^{\circ} \mathrm{C}$ of growth temperature and water-deficit (HT-WD).

New leaves were allowed to develop and expand under the two irrigation treatments for a minimum of 30 days. All measurements and samples were taken 40-50 days after the water treatment was initiated (i.e., 60-70 days after germination), on new leaves developed completely under the temperature and/or water treatments (Perdomo, 2015). Plants of all three species were in the vegetative stage and analyses used young fully expanded leaves.

Leaf samples for biochemical measurements were collected at mid-morning ( $4 \mathrm{~h}$ after the beginning of the photoperiod). Leaf disks of $0.5 \mathrm{~cm}^{2}$ were quickly frozen into liquid nitrogen and stored at $-80^{\circ} \mathrm{C}$ until extraction. These samples were used for the following determinations: Rubisco initial and total activity, activation state and amount, and Rubisco activase amount.

\section{Gas Exchange and Chlorophyll a Fluorescence Measurements}

All leaf gas exchange and chlorophyll a fluorescence measurements were performed on the youngest fully expanded leaf of each plant, using a portable photosynthesis system (Li-6400-40; Li-Cor Inc., USA) equipped with a leaf chamber fluorometer (Li-6400-40, Li-Cor Inc.), the latter using the multiflash protocol (Loriaux et al., 2013). The net $\mathrm{CO}_{2}$ assimilation rate $\left(A_{\mathrm{N}}\right)$ and the stomatal conductance $\left(g_{\mathrm{s}}\right)$ were measured at mid-morning at a leaf temperature of $25^{\circ} \mathrm{C}$, saturating PPFD of $1500 \mu \mathrm{mol} \mathrm{m} \mathrm{m}^{-2} \mathrm{~s}^{-1}$ (provided by the light source of the Li-6400-40, with $10 \%$ blue light), a $\mathrm{CO}_{2}$ concentration in the leaf chamber $\left(C_{\mathrm{a}}\right)$ of $400 \mu \mathrm{mol} \mathrm{CO} \mathrm{Col}^{-1}$ air and a relative humidity between 40 and 50\%. A PPFD of $1500 \mu \mathrm{mol}$ $\mathrm{m}^{-2} \mathrm{~s}^{-1}$ was considered to provide photosynthesis saturation for the glasshouse grown plants (Makino et al., 1994; Grassi and Magnani, 2005; Centritto et al., 2009; Ghannoum, 2009; Tazoe et al., 2009; Zhu et al., 2012; Xiong et al., 2015). The leaf dark respiration rate $\left(R_{\text {dark }}\right)$ was determined at pre-dawn (i.e., shortly before the start of the light period) at a $C_{a}$ of $400 \mu \mathrm{mol}$ $\mathrm{CO}_{2} \mathrm{~mol}^{-1}$ air. The gross $\mathrm{CO}_{2}$ assimilation rate $\left(A_{\mathrm{G}}\right)$ was calculated from the sum of $A_{\mathrm{N}}$ and half of $R_{\text {dark }}$ (Bermúdez et al., 2012).

The photochemical efficiency of photosystem II (ФPSII) was determined according to Genty et al. (1989):

$$
\Phi P S I I=\left(F_{\mathrm{m}}^{\prime}-\mathrm{F}_{\mathrm{s}}\right) / \mathrm{F}_{\mathrm{m}}^{\prime}
$$

where $F_{\mathrm{s}}$ is the steady-state fluorescence yield and $F_{\mathrm{m}}^{\prime}$ the maximum fluorescence yield obtained with a light-saturating pulse of $8000 \mu \mathrm{mol} \mathrm{m}^{-2} \mathrm{~s}^{-1}$.

The linear rate of electron transport (J) was calculated according to Krall and Edwards (1992):

$$
J=\Phi_{\mathrm{PSII}} \cdot \mathrm{PPFD} \cdot \alpha \cdot \beta
$$

where $\alpha$ is the leaf absorbance and $\beta$ is the partitioning of absorbed quanta between photosystems I and II. $\beta$ was assumed to be 0.5 for the $C_{3}$ species (Laisk and Loreto, 1996; Tosens et al., 2012) and 0.4 for maize (von Caemmerer, 2000). $\alpha$ was measured for all species grown under each treatment inside a dark chamber using the light source from the Li-6400-40 and a spectroradiometer (HR2000CG-UV-NIR; Ocean Optics Inc., USA), as described by Schultz (1996). All values obtained for $\alpha$ were $0.86-0.87$, with non-significant differences between species and species $\times$ treatment combinations.

\section{Estimation of $C_{c}, C_{s}$, and $g_{m}$}

From combined gas-exchange and chlorophyll $a$ fluorescence measurements, the mesophyll conductance to $\mathrm{CO}_{2}\left(g_{\mathrm{m}}\right)$ was estimated for wheat and rice using the so-called variable J method (Harley et al., 1992). The estimated value of $g_{\mathrm{m}}$ for wheat and rice, both $\mathrm{C}_{3}$ species, was used to calculate $C_{c}$ by applying the equation:

$$
C_{c}=C_{i}-\left(A_{\mathrm{N}} / g_{\mathrm{m}}\right)
$$

Maize has a $\mathrm{C}_{4}$-based carbon concentrating mechanism, with inherent complexity that complicates mathematical modeling (Collatz et al., 1992; von Caemmerer and Furbank, 1999; von Caemmerer, 2000; Ubierna et al., 2012). In this study, both $g_{\mathrm{m}}$ and $g_{\text {bs }}$ (bundle sheath conductance) were considered constant in maize (von Caemmerer, 2000; Massad et al., 2007; Ghannoum, 2009). Yin et al. (2016) have recently shown large variation in 
$g_{\text {bs }}$ in response to measurement temperature in maize plants grown at a constant temperature of $27^{\circ} \mathrm{C}$. To the best of our knowledge, there are no reports on the variation of $g_{\text {bs }}$ with growth temperature. Furthermore, a sensitivity analysis (results not shown) demonstrated that even large changes in $g_{\mathrm{m}}$ did not affect our results; we expect the same would hold true for $g_{\text {bs }}$. The $\mathrm{CO}_{2}$ concentration in the bundle sheath $\left(C_{s}\right)$ of maize leaves was estimated from the hyperbolic function describing the $A_{\mathrm{N}}-C_{\mathrm{i}}$ curves using the $\mathrm{C}_{4}$ photosynthesis model described by von Caemmerer (2000) as detailed by Massad et al. (2007) and with the modifications of Perdomo et al. (2016).

\section{Quantification of Photosynthetic Limitations}

To compare the relative limitations to $\mathrm{CO}_{2}$ assimilation induced by WD, HT and the combination of both stresses, the photosynthetic limitations were partitioned into their functional components following the approach proposed by Grassi and Magnani (2005). This approach uses values for $A_{\mathrm{G}}, g_{\mathrm{s}}$, and $g_{\mathrm{m}}$ (Supplementary Table S1) and the maximum rate of Rubisco carboxylation $\left(V_{\mathrm{cmax}}\right)$ as references. The maximum $A_{\mathrm{G}}$, concomitantly with $g_{\mathrm{s}}$ and $V_{\mathrm{cmax}}$, was reached under control conditions, therefore the control treatment was used as a reference. In the present study, $V_{\mathrm{cmax}}$ was calculated as the product of the Rubisco amount, the activation state and the carboxylase catalytic turnover rate $\left(k_{\mathrm{cat}}{ }^{\mathrm{c}}\right)$ measured in vitro at $25^{\circ} \mathrm{C}\left(2.1,2.2\right.$ and $4.1 \mathrm{~s}^{-1}$ for rice, wheat, and maize, respectively; Perdomo et al., 2016). Thereafter, the photosynthetic limitations were partitioned into components related to diffusion, i.e., stomatal $\left(S_{\mathrm{L}}\right)$ and mesophyll limitations $\left(\mathrm{MC}_{\mathrm{L}}\right)$, and leaf Rubiscobased biochemistry $\left(B_{\mathrm{L}}\right)$, estimated using the next equations:

$$
\begin{gathered}
D_{L}=S_{L}+M C_{L} \\
B_{L} \sim V_{\mathrm{cmax}}
\end{gathered}
$$

The analysis of biochemical limitations in maize was restricted to the $\mathrm{C}_{3}$ cycle activity. Data obtained under control conditions was used as the reference.

\section{Rubisco Activity and Amount in Leaf Crude Extracts}

Rubisco was extracted by grinding three leaf disk samples (total area of $1.5 \mathrm{~cm}^{2}$ ) in a mortar with $500 \mu \mathrm{L}$ of icecold extraction buffer containing $50 \mathrm{mM}$ Bicine- $\mathrm{NaOH} \mathrm{pH}$ 8.0, $1 \mathrm{mM}$ ethylene diamine tetracetic acid (EDTA), 5\% (w/v) polyvinylpyrrolidone (PVP), 6\% polyethylene glycol $\left(\mathrm{PEG}_{4000}\right)$, $50 \mathrm{mM} \beta$-mercaptoethanol, $10 \mathrm{mM}$ dithiothreitol (DTT) and 1\% (v/v) protease-inhibitor cocktail (Sigma-Aldrich Co. LLC., USA). Leaf extracts were then centrifuged at $14000 \times g$ for $1 \mathrm{~min}$ at $4^{\circ} \mathrm{C}$. The supernatant was kept at $4^{\circ} \mathrm{C}$ and used immediately for the measurement of Rubisco activity and amount.

The activities of Rubisco were determined by the incorporation of ${ }^{14} \mathrm{CO}_{2}$ into acid-stable products at a reaction temperature of $25^{\circ} \mathrm{C}$ for plants grown both at control and HT, following the protocol described in Parry et al. (1997). The reaction mixture $(500 \mu \mathrm{L})$ contained $100 \mathrm{mM}$ Bicine- $\mathrm{NaOH} \mathrm{pH}$ 8.2, $20 \mathrm{mM} \mathrm{MgCl}_{2}, 10 \mathrm{mM} \mathrm{NaH}{ }^{14} \mathrm{CO}_{3}\left(15.54 \mathrm{kBq} \mu \mathrm{mol}^{-1}\right)$ and $0.1 \mathrm{mM}$ RuBP. The initial activity was determined by adding $10 \mu \mathrm{L}$ of crude extract to the reaction mixture. The total activity was measured after incubating $10 \mu \mathrm{L}$ of the same extract for $3 \mathrm{~min}$ with all the components except RuBP, to allow carbamylation of all available Rubisco catalytic sites, and then starting the reaction by adding RuBP. All reactions were quenched after $60 \mathrm{~s}$ by adding $100 \mu \mathrm{L}$ of $10 \mathrm{M} \mathrm{HCOOH}$. The activation state of Rubisco was obtained as the ratio between the initial and total activities. All quenched reaction mixtures were completely dried at $100^{\circ} \mathrm{C}$, the residues dissolved in $400 \mu \mathrm{L}$ $\mathrm{H}_{2} \mathrm{O}$, mixed with $3.6 \mathrm{~mL}$ of Ultima Gold scintillation cocktail (PerkinElmer Inc., USA) and radioactivity due to the ${ }^{14} \mathrm{C}$ stable products determined in a liquid scintillation counter (LS-6500, Beckman Coulter Inc., USA).

The amount of Rubisco was measured by electrophoresis (Aranjuelo et al., 2005). One aliquot of the leaf crude extract was mixed with loading buffer, consisting of $65 \mathrm{mM}$ Tris- $\mathrm{HCl} \mathrm{pH}$ 6.8, $3 \mathrm{M}$ sucrose, 0.6 M $\beta$-mercaptoethanol, 5\% (w/v) sodium dodecyl sulphate (SDS), and $0.01 \%$ bromophenol blue. Samples were heated at $96^{\circ} \mathrm{C}$ for $5 \mathrm{~min}$ and then allowed to cool at room temperature. The total soluble protein (TSP) concentration in the crude extracts was determined by the method of Bradford (1976). A volume representing $15 \mu \mathrm{g}$ of TSP per sample (crude extract mixed with loading buffer) was loaded onto a $12.5 \%$ SDSpolyacrylamide gel (12.5\% resolving, $4 \%$ stacking; $0.75 \mathrm{~mm}$ thick; Bio-Rad Laboratories Inc., USA). This amount of protein was within the range of linear response of optical density for known concentrations of Rubisco purified from wheat (standard used for calibration). The solubilized proteins were separated by SDSPAGE (Laemmli, 1970) with electrophoresis being carried out at room temperature at a constant voltage $(200 \mathrm{~V})$. The gels were fixed in 500:150:75 (v/v/v) water-methanol-acetic acid mixture for $1 \mathrm{~h}$, stained in EZ Blue Gel Staining (Sigma-Aldrich Co. LLC., USA) solution for $1 \mathrm{~h}$ and subsequently rinsed in water to remove excess stain. Finally, the gels were scanned with a highresolution scanner (HP Scanjet G3010, Hewlett Packard, Spain) and the amount of large Rubisco subunit was determined by densitometry with the image analysis software TotalLab v2005 (Non-linear Dynamics, USA).

\section{Rubisco Activase Protein Amount}

The relative amount of Rca was measured by immunoblotting after separation of proteins by SDS-PAGE (Supplementary Figure S1; Salvucci et al., 2001). Soluble proteins were extracted from samples consisting of three leaf disks (total area of $1.5 \mathrm{~cm}^{2}$ ) by grinding in a mortar with $500 \mu \mathrm{L}$ of ice-cold extraction buffer containing $50 \mathrm{mM}$ Tricine- $\mathrm{NaOH}$ pH 8.0, $10 \mathrm{mM}$ EDTA, 1\% (w/v) PVP, $20 \mathrm{mM} \beta$-mercaptoethanol, $1 \mathrm{mM}$ phenylmethylsulfonyl fluoride (PMSF), $10 \mu \mathrm{M}$ leupeptin and $1 \%(\mathrm{v} / \mathrm{v})$ protease-inhibitor cocktail. The leaf extracts were centrifuged at $14000 \times g$ for $1 \mathrm{~min}$ at $4^{\circ} \mathrm{C}$ and $25 \mu \mathrm{L}$ of the supernatant was rapidly added to $20 \mu \mathrm{L}$ loading buffer (described above). After determination of the TSP concentration in the crude extracts, sample aliquots of extracts plus loading buffer corresponding to $6 \mu \mathrm{g}$ of TSP were loaded onto a 
12.5\% SDS-polyacrylamide gel (Bio-Rad Laboratories Inc., USA) and separated by electrophoresis at $100 \mathrm{~V}$. Serial dilutions of extracts prepared from leaf disks taken from plants of each species under control conditions were used as standards, by loading 5, 10, and $15 \mu \mathrm{g}$ of TSP. SDS-PAGE gels were blotted onto nitrocellulose membranes in $50 \mathrm{mM}$ Trizma base $/ 50 \mathrm{mM}$ boric acid for $1 \mathrm{~h}$ at $100 \mathrm{~V}$ within the Mini-Protean system (Bio-Rad Laboratories Inc., USA). Following blocking with $4 \%(\mathrm{w} / \mathrm{v})$ non-fat milk, blots were probed with monospecific antibodies (Salvucci et al., 2001). Immunodetection of Rca protein via colorimetry was carried out with the BCIP/NBT alkaline phosphatase system according to the manufacturer's instructions (Sigma-Aldrich Co. LLC., USA). The relative amount of Rubisco activase in each sample was determined by whole-band analysis of the membrane using an image acquisition densitometer (ChemiDoc XRS+ system, Bio-Rad Laboratories Inc., USA), with the image analysis software Quantity One v4.6.5 (Bio-Rad Laboratories Inc., USA).

\section{Statistical Analysis}

The statistical significance of trait variation was tested by factorial ANOVA, with species, irrigation treatments and growth temperatures as fixed factors, and the interaction between treatments. Post hoc comparison between treatments was performed using the Duncan test $(P<0.05)$ in the Statistica 6.0 software package (StatStof Inc., USA). Regression coefficients were calculated with the 11.0 Sigma Plot software package (Systat Software Inc., Germany).

\section{RESULTS}

\section{Photosynthetic Limitations in Cereals under Water Deficit and High Temperature}

The effects of WD and high growth temperature (HT) on the growth and physiology of rice, wheat and maize were addressed in previous studies (Perdomo et al., 2015, 2016). The detrimental effects of these two stresses on the gross $\mathrm{CO}_{2}$ assimilation rate $\left(A_{\mathrm{G}}\right)$ and stomatal $\left(g_{\mathrm{s}}\right)$ and mesophyll conductance $\left(g_{\mathrm{m}}\right)$ are shown in Supplementary Table S1. These data were used, together with maximum Rubisco carboxylation activity, to determine the contribution of the different types of limitations to photosynthesis under WD, HT, and HT-WD combination.

Under WD, the diffusive limitations $\left(D_{\mathrm{L}}\right)$ accounted for most of the photosynthetic limitations in wheat, while the biochemical limitations $\left(B_{\mathrm{L}}\right)$ were predominant in maize and both types of limitations had a similar contribution in rice (Figure 1A). Importantly, the analysis of the biochemical limitations in maize was restricted to the $\mathrm{C}_{3}$ cycle activity, taking into account those limitations associated with Rubisco, and not with the $\mathrm{C}_{4}$ cycle activity, including phosphoenolpyruvate carboxylase (PEPC). Under HT and the combination of the two stresses (HT-WD), the contribution of $B_{\mathrm{L}}$ was larger than that of $D_{L}$ and explained most of the inhibition of the photosynthetic $\mathrm{CO}_{2}$ assimilation in rice and maize, whereas both $B_{\mathrm{L}}$ and $D_{\mathrm{L}}$ limitations contributed

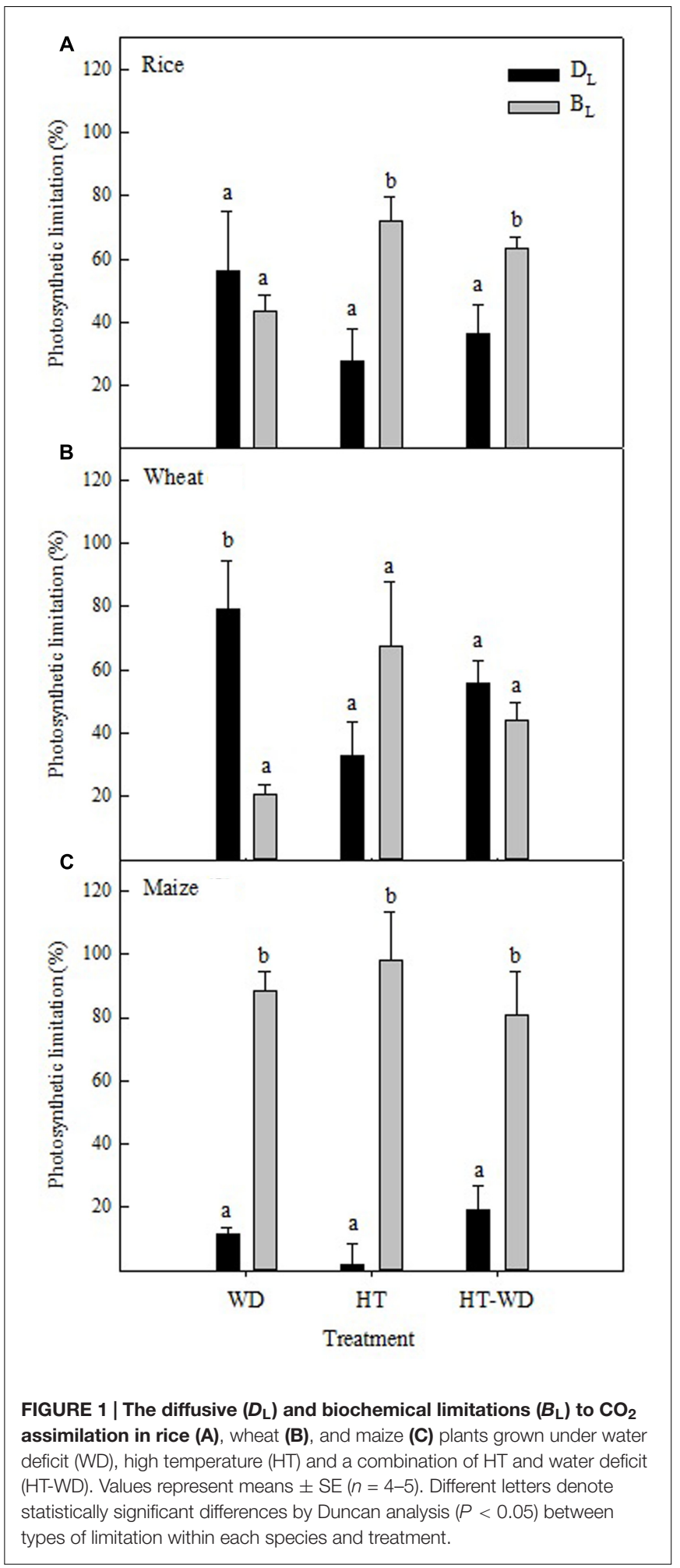

equally to the inhibition of photosynthesis in wheat under HT-WD (Figures 1B,C).

The relationship between the net $\mathrm{CO}_{2}$ assimilation rate $\left(A_{\mathrm{N}}\right)$ and the in vitro Rubisco activation provided further evidence for the observed photosynthetic limitations. At HT, the prevalence of 


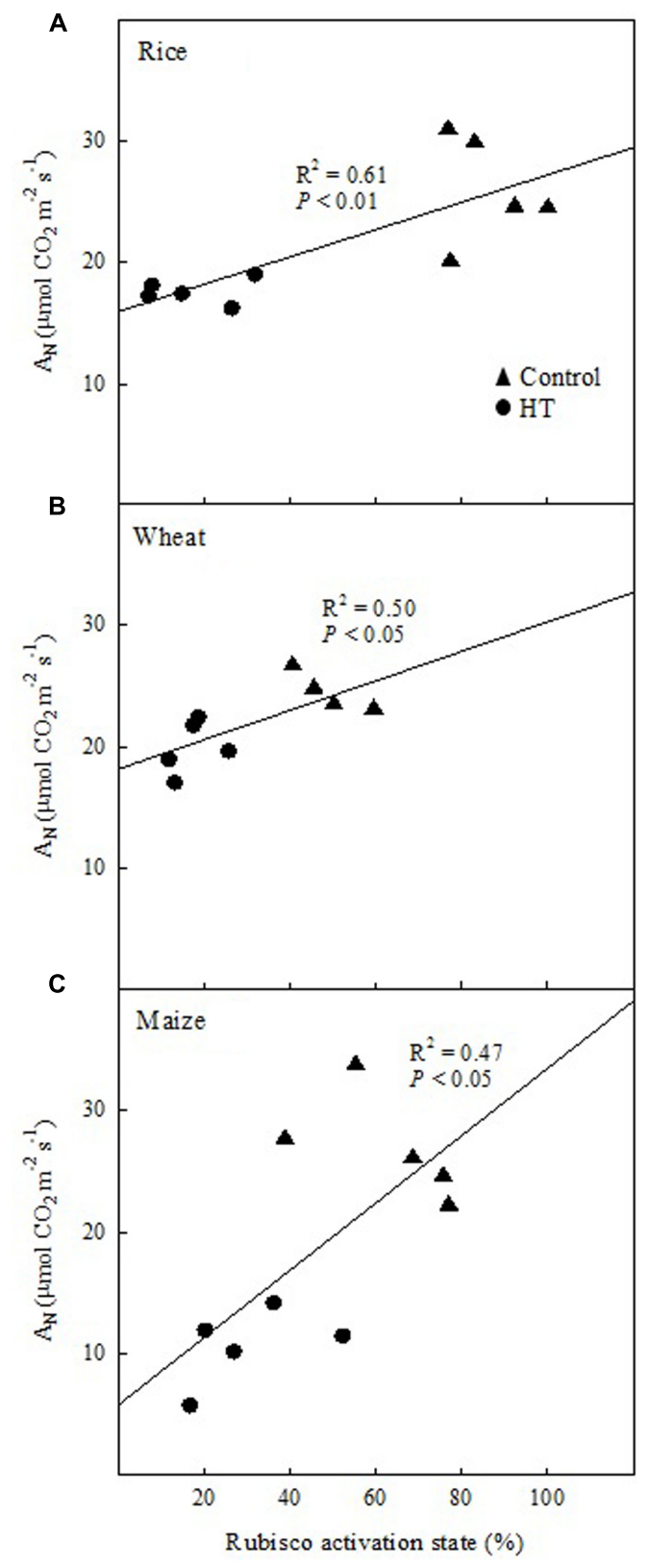

FIGURE 2 | The relationship between the Rubisco activation state and the net $\mathrm{CO}_{2}$ assimilation rate $\left(A_{N}\right)$ in well-watered plants of rice $(A)$, wheat (B), and maize (C) grown at $25^{\circ} \mathrm{C}$ (control) or $38^{\circ} \mathrm{C}(\mathrm{HT})$ and measured at $25^{\circ} \mathrm{C}$. Each symbol corresponds to one independent sample.

$B_{L}$ in the three species was confirmed by the positive correlation of $A_{\mathrm{N}}$ vs. Rubisco activation state in well-watered plants grown at $25^{\circ} \mathrm{C}$ or $38^{\circ} \mathrm{C}$ and measured at $25^{\circ} \mathrm{C}$ (Figure 2). Maize and rice showed decreases in $A_{\mathrm{N}}$ and Rubisco activation state with the increase in temperature (Figure 2). Under WD and HT-WD, the relationship, $A_{\mathrm{N}}$ vs. Rubisco activation state, was positive in rice $\left(R^{2}=0.51, P<0.05\right.$, data not shown), but not in wheat and maize $(P>0.05$, data not shown), in agreement with the limitation analysis (Figure 1A).

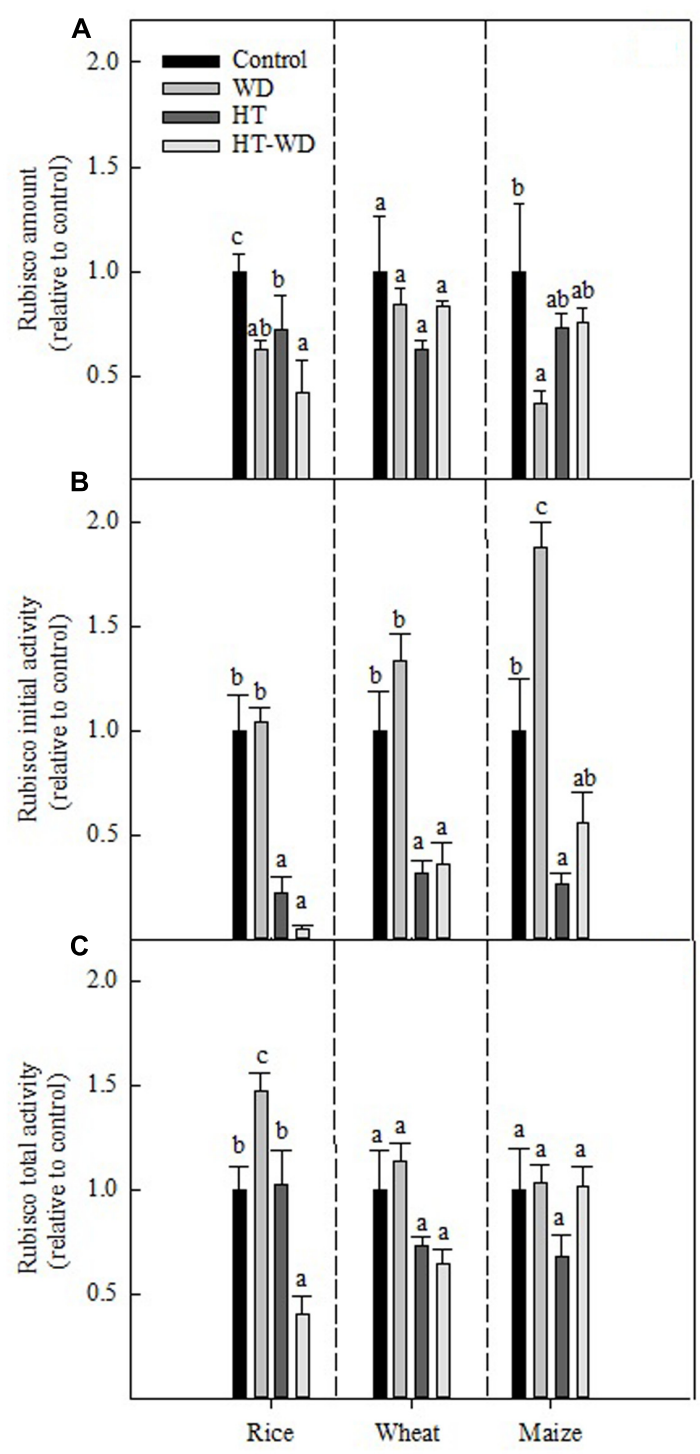

FIGURE 3 | Rubisco amount (A), initial (B) and total (C) activities at $25^{\circ} \mathrm{C}$ measured in plants of rice, wheat, and maize grown at control, WD, HT and a combination of HT and water deficit (HT-WD) conditions. To unify scales among the different species, values are means \pm SE $(n=4-5)$ of each parameter expressed relative to control plants. Different letters denote statistically significant differences by Duncan analysis $(P<0.05)$ among treatments within each species. The control values for rice, wheat, and maize of Rubisco amount were, respectively, $0.49 \pm 0.03,0.34 \pm 0.04$, $0.15 \pm 0.05$ mg Rubisco $\mathrm{mg}^{-1} \mathrm{TSP}$; Rubisco initial activity $0.31 \pm 0.02$, $0.19 \pm 0.04,0.08 \pm 0.01 \mu \mathrm{mol} \mathrm{CO}_{2} \mathrm{mg}^{-1} \mathrm{TSP} \mathrm{min}^{-1}$; and Rubisco total activity $0.36 \pm 0.01,0.44 \pm 0.05,0.13 \pm 0.02 \mu \mathrm{mol} \mathrm{CO}_{2} \mathrm{mg}^{-1} \mathrm{TSP}_{\mathrm{min}}^{-1}$.

\section{Rubisco Amount and Activities in Cereals under Water Deficit and High Temperature}

Water deficit and HT stresses affected the amount and activities of Rubisco in rice, wheat and maize differently, depending on the treatment and the species (Figure 3). Results are relative to the values obtained for control plants to facilitate comparison 


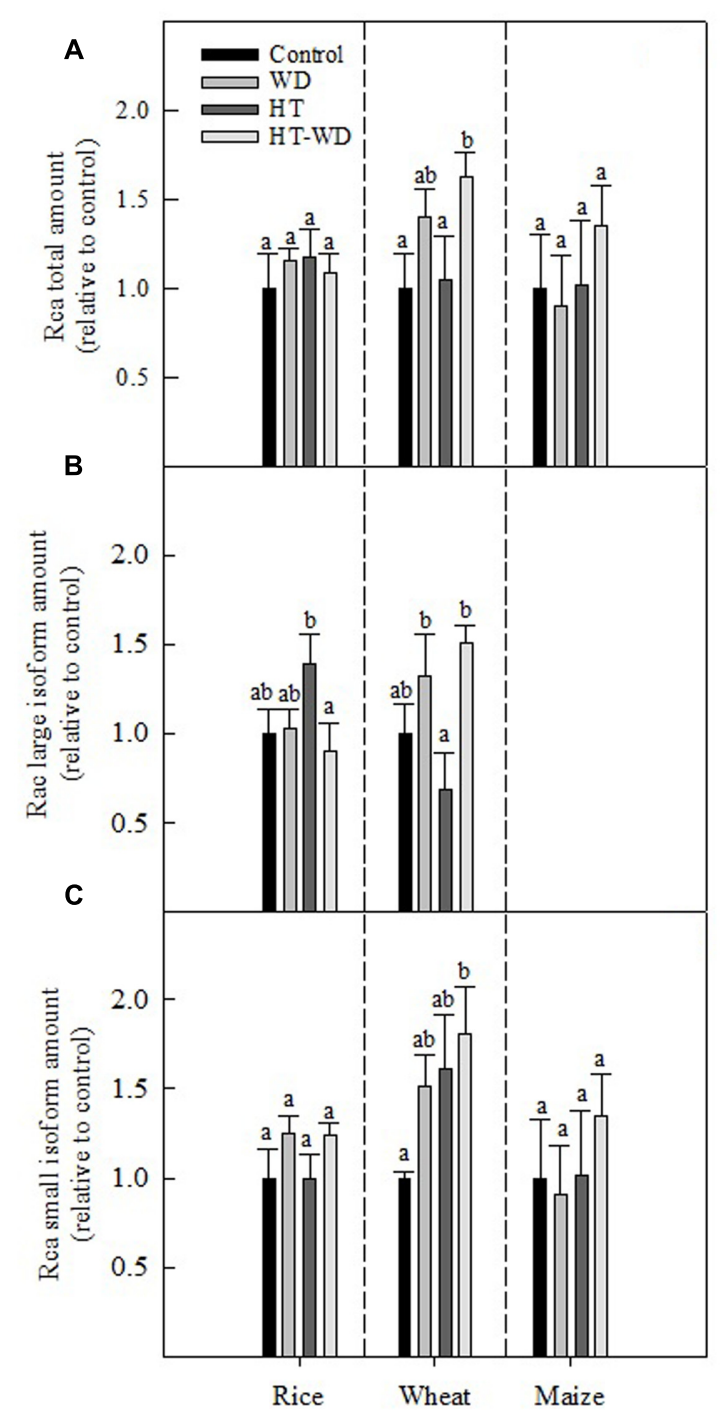

FIGURE 4 | Total Rubisco activase (Rca) amount (A), Rca large isoform amount (B) and Rca small isoform amount $(\mathbf{C})$ in plants of rice, wheat, and maize grown at control, WD, HT and a combination of HT and water deficit (HT-WD) conditions. Values represent means \pm SE $(n=4)$ of amounts expressed relative to control plants. Different letters denote statistically significant differences by Duncan analysis $(P<0.05)$ among treatments within each species.

among the three species. While the amount of Rubisco in wheat was not affected by any of the applied treatments, it decreased in rice and maize under $\mathrm{WD}$ and in rice plants grown at HT (Figure 3A). The combined HT-WD treatment was no more detrimental than the each of the individual stresses for any of the species; rice was the species with the largest decrease in Rubisco amount, with ca. 50\% less Rubisco under HT-WD compared to the control.

Rubisco initial activity was not affected negatively by WD in any of the three species (Figure 3B). In fact, maize showed an increase in the initial activity, to almost the double under WD compared to the control treatment. By contrast, Rubisco initial activity decreased severely in plants of the three species grown under HT. The combination HT-WD was not more detrimental than HT on its own, which suggests that Rubisco initial activity is more sensitive to inhibition by HT than by WD in these three species. As observed with the amount of Rubisco, rice showed the largest decrease in the initial activity of Rubisco under the combined stress treatment.

Rubisco total activity was less affected than the initial activity under the applied treatments (Figure 3C). In rice, Rubisco total activity decreased only under HT-WD and non-significant effects were observed in wheat and maize. Overall, the different response between the initial and total activities indicates that the applied treatments affected the Rubisco activation state, particularly under HT and HT-WD (Figures 3B,C).

\section{Rubisco Activase Amount in Cereals under Water Deficit and High Temperature}

The total amount of Rca relative to plants grown under control conditions was not significantly affected by WD and HTs, except in wheat where Rca increased in plants exposed to the combination HT-WD treatment (Figure 4A). With the exception of wheat, the Rca amount was constant under the different treatments, which indicates that the decrease in Rubisco activity was not due to a decrease in the total Rca amount. However, when the large and small Rca isoforms were quantified separately, some differences among treatments and species became apparent. The Rca large isoform was observed only in the two $C_{3}$ species; in rice the amount was higher at HT than HT-WD, whereas in wheat the amount was higher under WD and HT-WD than under HT alone (Figure 4B). The results suggest that the Rca large isoform is susceptible to HT in wheat. The amount of the small Rca isoform did not show significant differences among the treatments in rice and maize. Conversely, in wheat the amount of the small isoform increased considerably under the combined stresses HT-WD compared to control plants (Figure 4C).

\section{Rubisco Activation Dependence on the $\mathrm{CO}_{2}$ Availability, Rubisco and Rca Amounts, and Rate of Electron Transport}

The activation state of Rubisco was plotted in relation to the ratio of Rca/Rubisco amounts and to the concentration of $\mathrm{CO}_{2}$ in the chloroplast of the mesophyll and the bundle sheath cells $\left(C_{\mathrm{c}}\right.$ and $C_{s}$ ) in the two $C_{3}$ species and maize, respectively (Figure 5). Wheat and rice exhibited a similar pattern; under WD the decrease in the activation state of Rubisco was minor (in rice) or non-existent (in wheat), and were accompanied by moderate increases in the ratio of Rca/Rubisco amounts and decreases in $C_{\mathrm{c}}$ (Figures 5A-D). Rice and wheat plants grown under HT stress showed large decreases in Rubisco activation state, alongside with modest increases in the Rca/Rubisco amounts and no changes in $C_{\mathrm{c}}$. Maize presented a similar pattern to that observed in the $\mathrm{C}_{3}$ species, with the exception of WD plants which exhibited an increase in the activation state of Rubisco and a large increase in the ratio of Rca/Rubisco amounts (Figure 5E). 

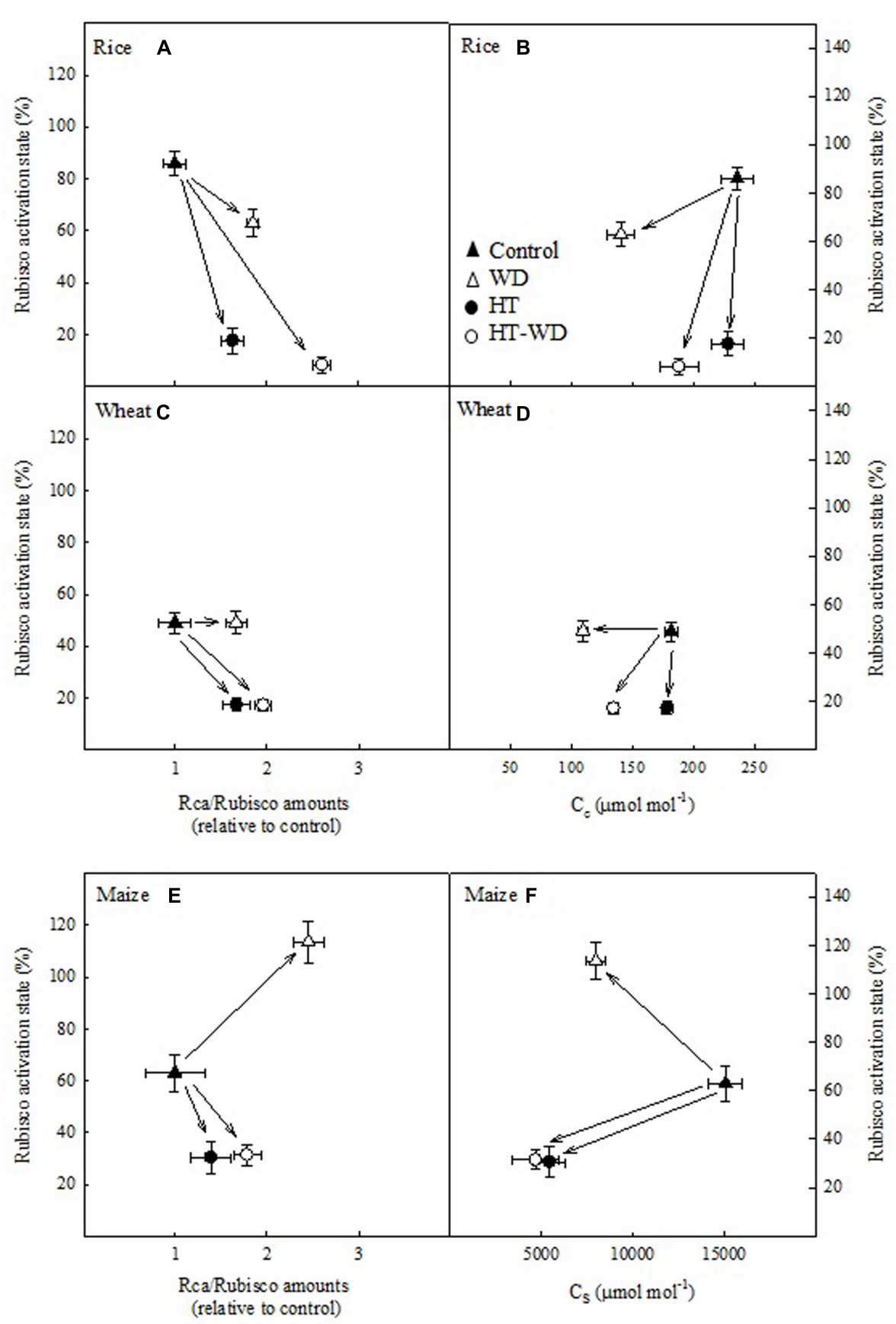

FIGURE 5 | Rubisco activation state in relation to the ratio of Rubisco activase (Rca) to Rubisco amounts (Rca/Rubisco; $\mathbf{A}, \mathbf{C}, \mathbf{E})$, the $\mathrm{CO}_{2}$ concentration in the mesophyll chloroplasts $\left(C_{C} ; \mathbf{B}, \mathbf{D}\right)$ or the bundle sheath $\left(C_{S} ; \mathbf{F}\right)$ in rice $(\mathbf{A}, \mathbf{B})$, wheat $(\mathbf{C}, \mathbf{D})$, and maize $(\mathbf{E}, \mathbf{F})$. Values represent means $\pm S E(n=4-5)$.

A positive relationship between the activation state of Rubisco and the ratio of Rca/Rubisco amounts would be expectable as there is more Rca to activate Rubisco. However, the results above suggest that changes in the activation of Rubisco are due to the combined effects of adjustments in the ratio of Rca/Rubisco amounts and in $C_{c}$ or $C_{s}$. In fact, increases in the ratio of $\mathrm{Rca} /$ Rubisco amounts correlated with decreases in $C_{\mathrm{c}}$ in rice $(P<0.05)$ and with decreases in $C_{s}$ in maize $(P<0.1)$ (Figure 6).
This correlation, which was not observed in wheat, suggests that rice and maize adjusted the ratio of $\mathrm{Rca} / \mathrm{Rubisco}$ amounts to the concentration of $\mathrm{CO}_{2}$ available for carboxylation, however, wheat varies Rca but not Rubisco amounts under the different treatments (Figure 3).

Rubisco activation state showed a significant positive correlation with the electron transport rate $(\mathrm{J})$ in the two $\mathrm{C}_{3}$ species (Figures $7 \mathrm{~A}, \mathbf{B}$ ). In rice and wheat, $J$ and Rubisco 

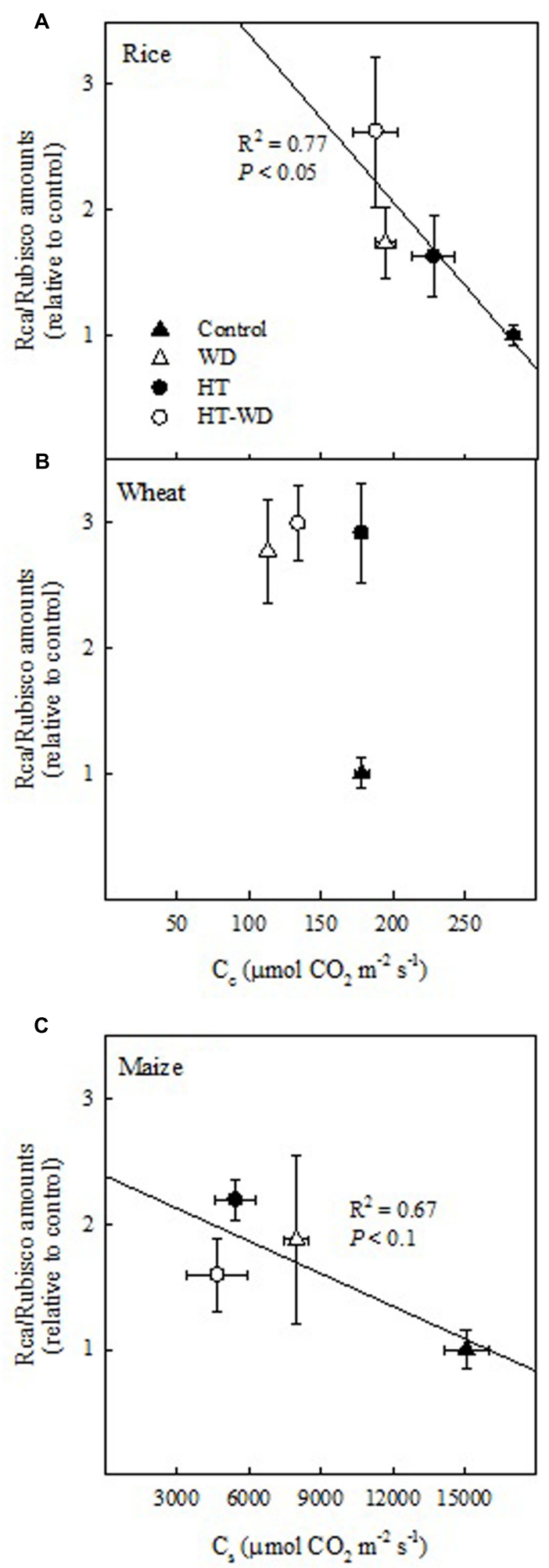

FIGURE 6 | The relationship between the $\mathrm{CO}_{2}$ concentration in the mesophyll chloroplasts $\left(\boldsymbol{C}_{\mathbf{c}}\right)$ in rice $(\mathbf{A})$ and wheat $(\mathbf{B})$ and the $\mathrm{CO}_{2}$ concentration in the bundle sheath chloroplasts $\left(C_{S}\right)$ in maize $(\mathbf{C})$ and the ratio of Rubisco activase (Rca) to Rubisco amounts (Rca/Rubisco). Values represent means \pm SE $(n=4-5)$. activation state decreased when the growth temperature increased, independently of the irrigation treatment. However, rice showed a slight decrease in $J$ and Rubisco activation state under WD at both growth temperatures, while wheat did not show any differences between well-watered and WD within each growth temperature. Therefore, rice was the species most affected by the combined HT-WD treatment. Although maize did not show a significant correlation between Rubisco activation state and J, the same pattern was apparent, with a decrease in both parameters at HT independent of the watering treatment (Figure 7C).

\section{DISCUSSION}

Water deficit and heat stress are two main factors adversely affecting crop productivity. The effects of these stresses, independently and in combination, on the physiological responses of three main cereals, wheat, rice and maize were examined in previous studies (Perdomo et al., 2015, 2016). In the present manuscript, the focus was on the response of the $\mathrm{CO}_{2}$-fixing enzyme, Rubisco, and of its molecular chaperone Rca. Additionally, physiological and biochemical data were combined to assess the type of limitations to photosynthesis under these two stresses. Although there was more than one plant per pot in rice and wheat, all plants had plentiful supply of nutrients for growth so as to avoid any interference with the effect of the stresses here studied.

\section{Photosynthesis Is Impaired by Diffusion Limitations under Water Deficit and Biochemical Limitations under High Temperature in Rice, Wheat, and Maize Plants Subjected to Long-term Stressful Conditions}

The results showed that diffusional limitations $\left(D_{\mathrm{L}}\right)$ constrained $\mathrm{CO}_{2}$ assimilation, at least in the two $\mathrm{C}_{3}$ species under WD, whereas biochemical limitations $\left(B_{\mathrm{L}}\right)$ were associated with the inhibition of photosynthesis under heat stress in all three species (Figure 1). These findings are in agreement with previous reports for other species (Chaves et al., 2003; Pinheiro and Chaves, 2011; Carmo-Silva et al., 2012).

Under WD, both of the $\mathrm{C}_{3}$ species exhibited reduced stomatal conductance $\left(g_{s}\right)$, while a decrease in mesophyll conductance $\left(g_{\mathrm{m}}\right)$ was also observed in rice (Supplementary Table S1). Hence, decreased capacity to transfer $\mathrm{CO}_{2}$ from the atmosphere to the chloroplast stroma under WD imposed a limitation on photosynthesis in the $\mathrm{C}_{3}$ species (Figure 1). Decreased $g_{\mathrm{s}}$ and $g_{\mathrm{m}}$ under WD have been shown to limit the $\mathrm{CO}_{2}$ concentration at the Rubisco site in the mesophyll cells $\left(C_{\mathrm{c}}\right)$ of $\mathrm{C}_{3}$ species and in the bundle-sheet cells $\left(C_{\mathrm{s}}\right)$ in $\mathrm{C}_{4}$ species (Flexas and Medrano, 2002a; Chaves et al., 2003; Ghannoum, 2009; Lopes et al., 2011). This finding was confirmed in the present study (Figure 5). In rice, the lower concentration of $\mathrm{CO}_{2}$ imposed a biochemical limitation by decreasing the activation state of Rubisco (Figure 5), which explains the similar contribution of 


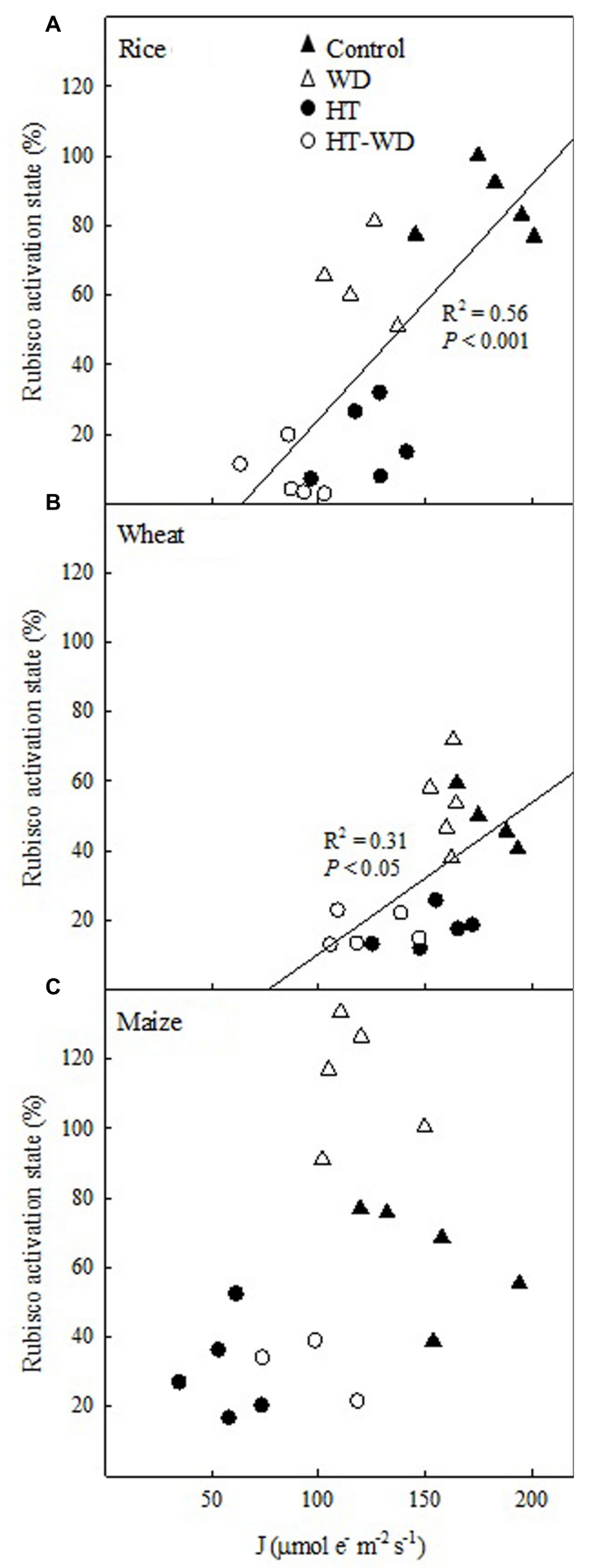

FIGURE 7 | The relationship between the Rubisco activation state and the electron transport rate (J) in rice (A), wheat (B), and maize (C).

$D_{L}$ and $B_{\mathrm{L}}$ under WD (Figure 1). On the contrary, decreased $C_{\mathrm{c}}$ in wheat under WD did not result in lower Rubisco activation state, which may explain why $B_{L}$ were less prominent in this species (Figure 1). These results suggest that Rubisco in rice is more sensitive to de-activation than wheat Rubisco at low $\mathrm{CO}_{2}$ availability. Different sensitivities of Rubisco de-activation under limiting $\mathrm{C}_{\mathrm{c}}$ have been reported among species from contrasting environments (Galmés et al., 2011). In both $\mathrm{C}_{3}$ species, rice and wheat, the ratio ETR $/ A_{\mathrm{G}}$ increased under WD (data not shown). This behavior is agreement with reports from literature in a large number of species (Flexas and Medrano, 2002b; Medrano et al., 2002; Salazar-Parra et al., 2012) indicating an increase in photorespiration under WD conditions.

Growth at HT did not alter $C_{\mathcal{c}}$, but decreased the activation state of Rubisco in rice and wheat (Figure 5), in agreement with the predominant role of $B_{\mathrm{L}}$ under HT (Figure 1). A recent report indicated that leaf conductances tend to remain unchanged and/or increase at measuring temperatures up to $40^{\circ} \mathrm{C}$ in rice and wheat plants grown at optimum temperatures (von Caemmerer and Evans, 2015). In our study, no changes were observed in $g_{s}$ in rice and wheat plants grown at HT and measured at $25^{\circ} \mathrm{C}$, and $g_{\mathrm{m}}$ decreased only in rice (Supplementary Table S1).

The analysis of limitations of the $\mathrm{C}_{3}$ cycle - Rubisco dependent - in maize revealed that $B_{\mathrm{L}}$ prevailed both under WD and HT (Figure 1), suggesting that the observed decrease in $C_{s}$ under WD was not limiting to $\mathrm{CO}_{2}$ assimilation rates (Supplementary Table S1 and Figure 5). Rubisco in maize was markedly affected by WD (decreased amount) and HT (decreased Rubisco activation state) (Figure 3). This decrease in Rubisco activation state in HT-grown maize was related to marked inhibition of photosynthetic capacity (Figure 2), as previously reported in this species (Crafts-Brandner and Salvucci, 2002; Sharwood et al., 2016). Although the analysis of photosynthetic limitations did not take into account the enzymes of the $\mathrm{C}_{4}$ cycle in maize, two of the key enzymes of $\mathrm{C}_{4}$ photosynthesis, pyruvate phosphate dikinase (PPDK) and PEPC, are insensitive to leaf temperatures up to $40^{\circ} \mathrm{C}$ in maize (Crafts-Brandner and Salvucci, 2002). Therefore, the results reported in the present study are in agreement with the notion that Rubisco regulation makes $\mathrm{C}_{4}$ photosynthesis as sensitive to inhibition by heat stress as $C_{3}$ photosynthesis (Crafts-Brandner and Salvucci, 2002; Ghannoum, 2009; von Caemmerer and Furbank, 2016), despite the fact that the $\mathrm{C}_{4} \quad \mathrm{CO}_{2}$-concentrating mechanism offers a greater buffering capacity against HT and the diffusion limitations under water stress.

Rubisco initial activity was also markedly affected in plants of all three species under the combined effect of HT-WD (Figure 3), which has been previously observed in different cotton cultivars (Carmo-Silva et al., 2012). In rice and maize, $B_{\mathrm{L}}$ were predominant under the combined treatment whereas in wheat, both $D_{\mathrm{L}}$ and $B_{\mathrm{L}}$ contributed to inhibit photosynthesis when the two stresses were imposed together (Figure 1). It is known that $\mathrm{WD}$ and $\mathrm{HT}$ limit photosynthesis in $\mathrm{C}_{3}$ (Flexas et al., 2004; $\mathrm{Hu}$ et al., 2010) and $\mathrm{C}_{4}$ species (Ripley et al., 2007; Ghannoum, 2009). While little is known about the detrimental effect of the combination of these two stresses, in the few studies where these effects have been measured, photosynthesis was highly sensitive to the combination of 
HT-WD (Prasad et al., 2008, 2011; Silva et al., 2010; Vile et al., 2012).

\section{Biochemical Limitations Are Mainly Attributed to Changes in the Rubisco Activation State via Adjustments in the Concentration of $\mathrm{CO}_{2}$, Rubisco/Rca Relative Amounts and Rca Activity}

To understand the effects of WD and HTs on photosynthesis, it is important to elucidate the biochemical components that are affected, particularly those associated with the Rubisco enzyme. WD effects on Rubisco are still unresolved, with some studies showing no effect (Vapaavuori, 1986; Pelloux et al., 2001) and others reporting decreases in Rubisco content and activation (Flexas et al., 2006b; Galmés et al., 2011). Some reports show that decreases in the Rubisco content and activity are associated with the severity of WD and are species-specific (Parry et al., 2002; Tezara et al., 2002; Bota et al., 2004). In rice and maize, but not in wheat, the amount of Rubisco decreased under WD, but Rubisco initial and total activities increased in maize and rice, respectively (Figure 3). Other authors have reported a decrease in the initial and total activities of Rubisco that has been attributed to a decrease in the Rubisco content (Flexas and Medrano, 2002a; Tezara et al., 2002; Bota et al., 2004; Galmés et al., 2013). In the present study, the increased Rubisco activity accompanied by a decrease in the Rubisco content in WD-maize was associated with a higher Rubisco activation state, probably triggered by an increased ratio Rca/Rubisco (Figure 5).

Several authors have reported that Rubisco amount is highly affected by growth at HTs (Verlag et al., 2002; Gesch et al., 2003; Pérez et al., 2011). In the present study, the Rubisco amount was significantly lower at HT only for rice (Figure 3). However, large decreases in the Rubisco initial activity were observed at HT in all three species, which were not accompanied by changes in the Rubisco total activity. Overall, these data indicate that growth at HT induced a decrease in the Rubisco activation state in the three species. Further, the decrease in the Rubisco activation state caused a decrease in the photosynthetic capacity of the three crop species (Figure 2), in agreement with previous reports (Crafts-Brandner and Salvucci, 2000; Salvucci and Crafts-Brandner, 2004; Yamori and von Caemmerer, 2009; Scafaro et al., 2012). This decrease in the Rubisco activation state at HT was unrelated to variations in the total amount of Rubisco and Rca in any of the three species (Figure 5). Rubisco activity was measured at $25^{\circ} \mathrm{C}$ for both control and HT plants and some of the effects of mildto-moderate heat stress on Rubisco activity and carbamylation state could have been lost when performing the assays at an optimal temperature (Galmés et al., 2013). However, others have also shown that temperature response of Rubisco activation does not appear to be strongly dependent on Rca content (Salvucci et al., 2006; Yamori and von Caemmerer, 2009). The total Rca amount remained unchanged across treatments in the three species (Figure 4), with the exception of wheat, for which Rca amount increased in the combined treatment HT-WD.

Rca is composed of small and large isoforms (Salvucci et al., 1987). Changes in the amount of the large Rca isoform in rice (slight increase) and wheat (slight decrease) at HT did not explain the large decreases in the Rubisco activation state (Figures 4,5$)$. These results are consistent with the hypothesis that the intrinsic heat sensitivity of Rca is linked with the observed decrease in Rubisco activation (Salvucci and CraftsBrandner, 2004; Barta et al., 2010; Carmo-Silva and Salvucci, 2011; Scafaro et al., 2016). On the other hand, decreased Rubisco activation state at $\mathrm{HT}$ correlated with the electron transport rate (J) in rice and wheat, irrespective of the watering treatment (Figure 7). This correlation did not hold for maize, a species that does not contain significant amounts of the large Rca isoform (Supplementary Figure S2; Salvucci et al., 1987). Lower $J$ at HT may result in decreased ATP/ADP ratios and redox potential in the chloroplast, which in turn, could affect the activity of Rca and, consequently, the capacity to restore the activity of Rubisco (Zhang and Portis, 1999; Zhang et al., 2002; Sage and Kubien, 2007; Carmo-Silva et al., 2015). In addition to decreased J in plants grown at HT, Rca activity may be also affected by other processes which have not been measured in the present study and cannot be ruled out. In particular, at HTs protons can leak through the thylakoid membrane, impairing the coupling of ATP synthesis to electron transport (Bukhov et al., 1999, 2000; Pastenesz and Horton, 2014; Singh et al., 2014).

\section{CONCLUSION}

In summary, photosynthesis was mainly affected by diffusive limitations under WD and by biochemical limitations at HT in rice, wheat and maize. Biochemical limitations were predominant also under the combination WD-HT in rice and maize. Increased biochemical limitations under HT were mainly attributed to decreased Rubisco activation state. In turn, decreased Rubisco activation was not related to altered amounts of Rca, but correlated with changes in the rate of electron transport. This result suggests that inhibited Rca activity was linked with the observed decrease in the Rubisco activation state, and ultimately, in the photosynthetic $\mathrm{CO}_{2}$ assimilation. Further research is required to verify whether increasing the thermal tolerance of Rca activity has the potential to increase photosynthesis at elevated temperatures. Since Rubisco activity impacts directly on the photosynthetic potential of plants, understanding the regulation of Rubisco and photosynthesis under heat stress is of pivotal importance to predict and mitigate consequences of future predicted climates on agriculture and natural ecosystems.

\section{AUTHOR CONTRIBUTIONS}

JAP performed the experiment, analyzed the data, and wrote the paper. SC-B contributed to the acquisition of the data. EC-S contributed to the design of the work, analysis and interpretation 
of the Rubisco activase data and to the preparation of the manuscript. JG obtained funding for the project, was a substantial contributor to the conception and design of the work and to the preparation of the manuscript.

\section{FUNDING}

This study was financially supported by the contract AGL200907999 (Plan Nacional, Spain) awarded to JG. JAP was the recipient of a FPI grant from the Govern de les Illes Balears. EC$S$ was the recipient of a Rothamsted Research Career Fellowship that currently supports JAP. Rothamsted Research receives grantaided support from the Biotechnology and Biological Sciences Research Council (BBSRC) 20:20 Wheat ${ }^{\circledR}$ Institute Strategic Programme.

\section{REFERENCES}

Aranjuelo, I., Perez, P., Hernandez, L., Irigoyen, J. J., Zita, G., MartinezCarrasco, R., et al. (2005). The response of nodulated alfalfa to water supply, temperature and elevated CO2: photosynthetic downregulation. Physiol. Plant. 123, 348-358. doi: 10.1111/j.1399-3054.2005.00459.x

Barta, C., Dunkle, A. M., Wachter, R. M., and Salvucci, M. E. (2010). Structural changes associated with the acute thermal instability of Rubisco activase. Arch. Biochem. Biophys. 499, 17-25. doi: 10.1016/j.abb.2010.04.022

Bermúdez, M. Á, Galmés, J., Moreno, I., Mullineaux, P. M., Gotor, C., and Romero, L. C. (2012). Photosynthetic adaptation to length of day is dependent on S-sulfocysteine synthase activity in the thylakoid lumen. Plant Physiol. 160, 274-288. doi: 10.1104/pp.112.201491

Bernacchi, C. J., Portis, A. R., Nakano, H., von Caemmerer, S., and Long, S. P. (2002). Temperature response of mesophyll conductance. Implications for the determination of Rubisco enzyme kinetics and for limitations to photosynthesis in vivo. Plant Physiol. 130, 1992-1998. doi: 10.1104/pp.008250.water

Bota, J., Medrano, H., and Flexas, J. (2004). Is photosynthesis limited by decreased Rubisco activity and RuBP content under progressive water stress? New Phytol. 162, 671-681. doi: 10.1111/j.1469-8137.2004.01056.x

Bradford, M. M. (1976). A rapid and sensitive method for the quantitation of microgram quantities of protein utilizing the principle of protein-dye binding. Anal. Biochem. 72, 248-254. doi: 10.1016/0003-2697(76)90527-3

Bukhov, N., Wiese, C., Neimanis, S., and Heber, U. (1999). Heat sensitivity of chloroplasts and leaves: leakage of protons from thylakoids and reversible activation of cyclic electron transport. Photosynth. Res. 59, 81-93. doi: 10.1023/ A:1006149317411

Bukhov, N. G., Samson, G., and Carpenter, R. (2000). Nonphotosynthetic reduction of the intersystem electron transport chain of chloroplasts following heat stress. Photochem. Photobiol. 72, 351-357. doi: 10.1562/0031-8655(2000) 0720351NROTIE2.0.CO2

Carmo-Silva, A. E., Gore, M. A., Andrade-Sanchez, P., French, A. N., Hunsaker, D. J., and Salvucci, M. E. (2012). Decreased CO2 availability and inactivation of Rubisco limit photosynthesis in cotton plants under heat and drought stress in the field. Environ. Exp. Bot. 83, 1-11. doi: 10.1016/j.envexpbot.2012.04.001

Carmo-Silva, A. E., and Salvucci, M. E. (2011). The activity of Rubisco's molecular chaperone, Rubisco activase, in leaf extracts. Photosynth. Res. 108, 143-155. doi: 10.1007/s11120-011-9667-8

Carmo-Silva, A. E., and Salvucci, M. E. (2013). The regulatory properties of Rubisco activase differ among species and affect photosynthetic induction during light transitions. Plant Physiol. 161, 1645-1655. doi: 10.1104/pp.112.21 3348

Carmo-Silva, E., Scales, J. C., Madgwick, P. J., and Parry, M. A. J. (2015). Optimizing Rubisco and its regulation for greater resource use efficiency. Plant Cell Environ. 38, 1817-1832. doi: 10.1111/pce.12425

Centritto, M., Lauteri, M., Monteverdi, M. C., and Serraj, R. (2009). Leaf gas exchange, carbon isotope discrimination, and grain yield in contrasting rice

\section{ACKNOWLEDGMENTS}

We thank Dr. M. E. Salvucci for his helpful, critical contributions while revising the manuscript. Trinidad García (radioisotope service at UIB) for technical assistance with the radioactive measurements and Miquel Truyols for technical assistance at the greenhouse. The manuscript resulted from the Ph.D. thesis of JAP "Acclimation of photosynthesis to WD and HT: physiological and biochemical aspects.”

\section{SUPPLEMENTARY MATERIAL}

The Supplementary Material for this article can be found online at: http://journal.frontiersin.org/article/10.3389/fpls.2017.00490/ full\#supplementary-material

genotypes subjected to water deficits during the reproductive stage. J. Exp. Bot. 60, 2325-2339. doi: 10.1093/jxb/erp123

Chaves, M., Maroco, J., and Pereira, J. (2003). Understanding plant responses to drought-from genes to the whole plant. Funct. Plant Biol. 30, 239-264. doi: 10.1071/FP02076

Chaves, M. M., Flexas, J., and Pinheiro, C. (2009). Photosynthesis under drought and salt stress: regulation mechanisms from whole plant to cell. Ann. Bot. 103, 551-560. doi: 10.1093/aob/mcn 125

Collatz, G. J., Ribas-Carbo, M., and Berry, J. A. (1992). Coupled photosynthesisstomatal conductance model for leaves of C4 plants. Aust. J. Plant Physiol. 19, 519-539. doi: 10.1071/PP9920519

Crafts-Brandner, S. J., and Salvucci, M. E. (2000). Rubisco activase constrains the photosynthetic potential of leaves at high temperature and CO2. Proc. Natl. Acad. Sci. U.S.A. 97, 13430-13435. doi: 10.1073/pnas.230451497

Crafts-Brandner, S. J., and Salvucci, M. E. (2002). Sensitivity of photosynthesis in a C4 plant, maize, to heat stress. Plant Physiol. 129, 1773-1780. doi: 10.1104/pp. 002170.or

Dore, M. H. I. (2005). Climate change and changes in global precipitation patterns: what do we know? Environ. Int. 31, 1167-1181. doi: 10.1016/j.envint.2005. 03.004

Dreyer, E., Le Roux, X., Montpied, P., Daudet, F. A., and Masson, F. (2001). Temperature response of leaf photosynthetic capacity in seedlings from seven temperate tree species. Tree Physiol. 21, 223-232. doi: 10.1093/treephys/ 21.4.223

Evans, J. R., and von Caemmerer, S. (2013). Temperature response of carbon isotope discrimination and mesophyll conductance in tobacco. Plant. Cell Environ. 36, 745-756. doi: 10.1111/j.1365-3040.2012.02591.x

Flexas, J., Bota, J., Galmes, J., Medrano, H., and Ribas-Carbó, M. (2006a). Keeping a positive carbon balance under adverse conditions: responses of photosynthesis and respiration to water stress. Physiol. Plant. 127, 343-352. doi: 10.1111/j. 1399-3054.2005.00621.x

Flexas, J., Bota, J., Loreto, F., Cornic, G., and Sharkey, T. D. (2004). Diffusive and metabolic limitations to photosynthesis under drought and salinity in C3 plants. Plant Biol. (Stuttg). 6, 269-279. doi: 10.1055/s-2004-820867

Flexas, J., Escalona, J. M., and Medrano, H. (1999). Water stress induces different levels of photosynthesis and electron transport rate regulation in grapevines. Plant Cell Environ. 22, 39-48. doi: 10.1046/j.1365-3040.1999.00371.x

Flexas, J., and Medrano, H. (2002a). Drought-inhibition of photosynthesis in C3 plants: stomatal and non-stomatal limitations revisited. Ann. Bot. 89, 183-189. doi: $10.1093 / \mathrm{aob} / \mathrm{mcf0} 27$

Flexas, J., and Medrano, H. (2002b). Review: energy dissipation in C3 plants under drought. Funct. Plant Biol. 29, 1209-1215. doi: 10.1071/FP02015

Flexas, J., Ribas-Carbó, M., Bota, J., Galmés, J., Henkle, M., Martínez-Cañellas, S., et al. (2006b). Decreased Rubisco activity during water stress is not induced by decreased relative water content but related to conditions of low stomatal conductance and chloroplast CO2 concentration. New Phytol. 172, 73-82. doi: $10.1111 /$ j.1469-8137.2006.01794.x 
Galmés, J., Abadía, A., Cifre, J., Medrano, H., and Flexas, J. (2007a). Photoprotection processes under water stress and recovery in Mediterranean plants with different growth forms and leaf habits. Physiol. Plant. 130, 495-510. doi: 10.1111/j.1399-3054.2007.00919.x

Galmés, J., Aranjuelo, I., Medrano, H., and Flexas, J. (2013). Variation in Rubisco content and activity under variable climatic factors. Photosynth. Res. 117, 73-90. doi: 10.1007/s11120-013-9861-y

Galmés, J., Medrano, H., and Flexas, J. (2007b). Photosynthetic limitations in response to water stress and recovery in Mediterranean plants with different growth forms. New Phytol. 175, 81-93. doi: 10.1111/j.1469-8137.2007.02087.x

Galmés, J., Ribas-Carbó, M., Medrano, H., and Flexas, J. (2011). Rubisco activity in Mediterranean species is regulated by the chloroplastic CO2 concentration under water stress. J. Exp. Bot. 62, 653-665. doi: 10.1093/jxb/erq303

Genty, B., Briantais, J., and Baker, N. (1989). The relationship between the quantum yield of photosynthetic electron transport and quenching of chlorophyll fluorescence. Biochim. Biophys. Acta 990, 87-92. doi: 10.1016/S0304-4165(89) 80016-9

Gesch, R. W., Kang, I., Vu, J. C. V., Boote, K. J., Allen, L. H., and Bowes, G. (2003). Rubisco expression in rice leaves is related to genotypic variation of photosynthesis under elevated growth CO2. Plant Cell Environ. 26, 1941-1950. doi: 10.1046/j.1365-3040.2003.01110.x

Ghannoum, O. (2009). C4 photosynthesis and water stress. Ann. Bot. 103, 635-644. doi: $10.1093 / \mathrm{aob} / \mathrm{mcn} 093$

Grassi, G., and Magnani, F. (2005). Stomatal, mesophyll conductance and biochemical limitations to photosynthesis as affected by drought and leaf ontogeny in ash and oak trees. Plant Cell Environ. 28, 834-849. doi: 10.1111/ j.1365-3040.2005.01333.x

Gunderson, C., Norby, R., and Wullschleger, S. (2000). Acclimation of photosynthesis and respiration to simulated climatic warming in northern and southern populations of Acer saccharum: laboratory and field evidence. Tree Physiol. 20, 87-96. doi: 10.1093/treephys/20.2.87

Harley, P. C., Loreto, F., Di Marco, G., and Sharkey, T. D. (1992). Theoretical considerations when estimating the mesophyll conductance to $\mathrm{CO} 2$ flux by analysis of the response of photosynthesis to CO2. Plant Physiol. 98, 1429-1436. doi: 10.1104/pp.98.4.1429

Hu, L., Wang, Z., and Huang, B. (2010). Diffusion limitations and metabolic factors associated with inhibition and recovery of photosynthesis from drought stress in a C3 perennial grass species. Physiol. Plant. 139, 93-106. doi: 10.1111/j.1399-3054.2010.01350.x

IPCC (2013). Working Group I Contribution to the IPCC Fifth Assessment Report Climate Change 2013: The Physical Science Basis Summary for Policymakers. Geneva: IPCC.

Kim, K., and Portis, A. R. (2005). Temperature dependence of photosynthesis in Arabidopsis plants with modifications in Rubisco activase and membrane fluidity. Plant Cell Physiol. 46, 522-530. doi: 10.1093/pcp/pci052

Krall, J., and Edwards, G. (1992). Relationship between photosystem II activity and CO2 fixation in leaves. Physiol. Plant. 86, 180-187. doi: 10.1111/j.1399-3054. 1992.tb01328.x

Laemmli, U. (1970). Cleavage of structural proteins during the assembly of the head of bacteriophage T4. Nature 227, 680-685. doi: 10.1038/227680a0

Laisk, A., and Loreto, F. (1996). Determining photosynthetic parameters from leaf CO2 exchange and chlorophyll fluorescence. Plant Physiol. 110, 903-912. doi: $10.1104 /$ pp.110.3.903

Lopes, M. S., Araus, J. L., van Heerden, P. D. R., and Foyer, C. H. (2011). Enhancing drought tolerance in C4 crops. J. Exp. Bot. 62, 3135-3153. doi: 10.1093/jxb/ err105

Loriaux, S. D., Avenson, T. J., Welles, J. M., McDermitt, D. K., Eckles, R. D., Riensche, B., et al. (2013). Closing in on maximum yield of chlorophyll fluorescence using a single multiphase flash of sub-saturating intensity. Plant. Cell Environ. 36, 1755-1770. doi: 10.1111/pce.12115

Massad, R. S., Tuzet, A., and Bethenod, O. (2007). The effect of temperature on C4-type leaf photosynthesis parameters. Plant. Cell Environ. 30, 1191-1204. doi: 10.1111/j.1365-3040.2007.01691.x

Mathur, S., Agrawal, D., and Jajoo, A. (2014). Photosynthesis: response to high temperature stress. J. Photochem. Photobiol. B 137, 116-126. doi: 10.1016/j. jphotobiol.2014.01.010

Makino, A., Nakano, H., and Mae, T. (1994). Effects of growth temperature on the responses of ribulose-1,5-biphosphate carboxylase, electron transport components, and sucrose synthesis enzymes to leaf nitrogen in rice, and their relationships to photosynthesis. Plant Physiol. 105, 1231-1238. doi: 10.1104/pp. 105.4.1231

Medrano, H., Escalona, J. M., Bota, J., Gulías, J., and Flexas, J. (2002). Regulation of photosynthesis of $\mathrm{C} 3$ plants in response to progressive drought: stomatal conductance as a reference parameter. Ann. Bot. 89, 895-905. doi: 10.1093/aob/ $\operatorname{mcf079}$

Mott, K. A., and Woodrow, I. E. (2000). Modelling the role of Rubisco activase in limiting non-steady-state photosynthesis. J. Exp. Bot. 51, 399-406. doi: 10.1093/ jexbot/51.suppl_1.399

Panković, D., Sakac, Z., Kevresan, S., and Plesnicar, M. (1999). Acclimation to long-term water deficit in the leaves of two sunflower hybrids: photosynthesis, electron transport and carbon metabolism. J. Exp. Bot. 50, 127-138. doi: $10.1093 /$ jexbot/50.330.127

Parry, M. A. J., Andralojc, P., Khan, S., Lea, P., and Keys, A. J. (2002). Rubisco activity: effects of drought stress. Ann. Bot. 89, 833-839. doi: 10.1093/aob/ $\operatorname{mcf} 103$

Parry, M. A. J., Andralojc, P. J., Parmar, S., Keys, A. J., Habash, D., Paul, M. J., et al. (1997). Regulation of Rubisco by inhibitors in the light. Plant. Cell Environ. 20, 528-534. doi: 10.1046/j.1365-3040.1997.d01-85.x

Pastenesz, C., and Horton, P. (2014). Effect of high temperature on photosynthesis in beans. Plant Physiol. 112, 1245-1251. doi: 10.1104/pp.112.3.1245

Pelloux, J., Jolivet, Y., Fontaine, V., Banvoy, J., and Dizengremel, P. (2001). Changes in Rubisco and Rubisco activase gene expression and polypeptide content in Pinus halepensis M. subjected to ozone and drought. Plant Cell Environ. 24, 123-131. doi: 10.1046/j.1365-3040.2001.00665.x

Perdomo, J. A. (2015). Acclimation of Photosynthesis to Water Deficit and High Temperature: Physiological and Biochemical Aspects. Ph.D. thesis, University of the Balearic Islands, Palma de Mallorca.

Perdomo, J. A., Carmo-Silva, E., Hermida-Carrera, C., Flexas, J., and Galmés, J. (2016). Acclimation of biochemical and diffusive components of photosynthesis in rice, wheat and maize to heat and water deficit: implications for modeling photosynthesis. Front. Plant Sci 7:1719. doi: 10.3389/fpls.2016. 01719

Perdomo, J. A., Conesa, M. À, Medrano, H., Ribas-Carbó, M., and Galmés, J. (2015). Effects of long-term individual and combined water and temperature stress on the growth of rice, wheat and maize: relationship with morphological and physiological acclimation. Physiol. Plant. 155, 149-165. doi: 10.1111/ppl. 12303

Pérez, P., Alonso, A., Zita, G., Morcuende, R., and Martínez-Carrasco, R. (2011). Down-regulation of Rubisco activity under combined increases of $\mathrm{CO} 2$ and temperature minimized by changes in Rubisco kcat in wheat. Plant Growth Regul. 65, 439-447. doi: 10.1007/s10725-011-9613-y

Pinheiro, C., and Chaves, M. M. (2011). Photosynthesis and drought: can we make metabolic connections from available data? J. Exp. Bot. 62, 869-882. doi: $10.1093 /$ jxb/erq340

Prasad, P., Staggenborg, S., and Ristic, Z. (2008). "Impacts of drought and/or heat stress on physiological, developmental, growth, and yield processes of crop plants," in Modeling Water Stress Effects on Plant Growth Processes, eds L. Ahuja and S. Saseendran (Madison, WI: CROP Science Society of America), 301-356.

Prasad, P. V. V., Pisipati, S. R., Momćilović, I., and Ristic, Z. (2011). Independent and combined effects of high temperature and drought stress during grain filling on plant yield and chloroplast EF-Tu expression in spring wheat. J. Agron. Crop Sci. 197, 430-441. doi: 10.1111/j.1439-037X.2011.00477.x

Ripley, B. S., Gilbert, M. E., Ibrahim, D. G., and Osborne, C. P. (2007). Drought constraints on $\mathrm{C} 4$ photosynthesis: stomatal and metabolic limitations in $\mathrm{C} 3$ and C4 subspecies of Alloteropsis semialata. J. Exp. Bot. 58, 1351-1363. doi: $10.1093 /$ jxb/erl302

Sage, R. F., and Kubien, D. S. (2007). The temperature response of C3 and C4 photosynthesis. Plant Cell Environ. 30, 1086-1106. doi: 10.1111/j.1365-3040. 2007.01682.x

Salazar-Parra, C., Aguirreolea, J., Sánchez-Díaz, M., Irigoyen, J. J., and Morales, F. (2012). Photosynthetic response of Tempranillo grapevine to climate change scenarios. Ann. Appl. Biol. 161, 277-292. doi: 10.1111/j.1744-7348.2012. 00572.x

Salvucci, M. E., and Crafts-Brandner, S. J. (2004). Relationship between the heat tolerance of photosynthesis and the thermal stability of Rubisco activase in 
plants from contrasting thermal environments. Plant Physiol. 134, 1460-1470. doi: 10.1104/pp.103.038323.1460

Salvucci, M. E., DeRidder, B. P., and Portis, A. R. J. (2006). Effect of activase level and isoform on the thermotolerance of photosynthesis in Arabidopsis. J. Exp. Bot. 57, 3793-3799. doi: 10.1093/jxb/erl140

Salvucci, M. E., Osteryoung, K. W., Crafts-brandner, S. J., and Vierling, E. (2001). Exceptional sensitivity of Rubisco activase to thermal denaturation in vitro and in vivo. Plant Physiol. 127, 1053-1064. doi: 10.1104/pp.010357.1

Salvucci, M. E., Portis, A. R. J., and Ogren, W. (1985). A soluble chloroplast protein catalyzes ribulosebisphosphate carboxylase/oxygenase activation in vivo. Photosynth. Res. 7, 193-201. doi: 10.1007/BF00037012

Salvucci, M. E., Werneke, J., Ogren, W., and Portis, A. R. J. (1987). Purification and species distribution of Rubisco activase. Plant Physiol. 84, 930-936. doi: $10.1104 / p p .84 .3 .930$

Scafaro, A. P., Gallé, A., Van Rie, J., Carmo-Silva, E., Salvucci, M. E., and Atwell, B. J. (2016). Heat tolerance in a wild Oryza species is attributed to maintenance of Rubisco activation by a thermally stable Rubisco activase ortholog. New Phytol. 211, 899-911. doi: 10.1111/nph.13963

Scafaro, A. P., Yamori, W., Carmo-Silva, A. E., Salvucci, M. E., von Caemmerer, S., and Atwell, B. J. (2012). Rubisco activity is associated with photosynthetic thermotolerance in a wild rice (Oryza meridionalis). Physiol. Plant. 146, 99-109. doi: 10.1111/j.1399-3054.2012.01597.x

Scales, J. C., Parry, M. A. J., and Salvucci, M. E. (2014). A non-radioactive method for measuring Rubisco activase activity in the presence of variable ATP: ADP ratios, including modifications for measuring the activity and activation state of Rubisco. Photosynth. Res. 119, 355-365. doi: 10.1007/s11120-0139964-5

Schrader, S. M., Wise, R. R., Wacholtz, W. F., Ort, D. R., and Sharkey, T. D. (2004). Thylakoid membrane responses to moderately high leaf temperature in Pima cotton. Plant Cell Environ. 27, 725-735. doi: 10.1111/j.1365-3040.2004. 01172.x

Schultz, H. (1996). Leaf absorptance of visible radiation in Vitis vinifera L.: estimates of age and shade effects with a simple field method. Sci. Hortic. (Amsterdam). 66, 93-102. doi: 10.1016/0304-4238(96)00876-X

Sharwood, R. E., Sonawane, B. V., Ghannoum, O., and Whitney, S. M. (2016). Improved analysis of $\mathrm{C} 4$ and $\mathrm{C} 3$ photosynthesis via refined in vitro assays of their carbon fixation biochemistry. J. Exp. Bot. 67, 3137-3148. doi: 10.1093/jxb/ erw154

Silva, E. N., Ferreira-Silva, S. L., Fontenele, A. V., Ribeiro, R. V., Viégas, R. A., and Silveira, J. A. G. (2010). Photosynthetic changes and protective mechanisms against oxidative damage subjected to isolated and combined drought and heat stresses in Jatropha curcas plants. J. Plant. Physiol. 167, 1157-1167. doi: 10.1016/j.jplph.2010.03.005

Singh, J., Pandey, P., James, D., Chandrasekhar, K., Achary, V. M. M., Kaul, T., et al. (2014). Enhancing C3 photosynthesis: an outlook on feasible interventions for crop improvement. Plant Biotechnol. J. 12, 1217-1230. doi: 10.1111/pbi.12246

Spreitzer, R. J., and Salvucci, M. E. (2002). Rubisco: structure, regulatory interactions, and possibilities for a better enzyme. Annu. Rev. Plant Biol. 53, 449-475. doi: 10.1146/annurev.arplant.53.100301.135233

Tazoe, Y., von Caemmerer, S., Badger, M. R., and Evans, J. R. (2009). Light and $\mathrm{CO}_{2}$ do not affect the mesophyll conductance to $\mathrm{CO}_{2}$ diffusion in wheat leaves. J. Exp. Bot. 60, 2291-2301. doi: 10.1093/jxb/erp035

Tezara, W., Mitchell, V., Driscoll, S. P., and Lawlor, D. (2002). Effects of water deficit and its interaction with $\mathrm{CO} 2$ supply on the biochemistry and physiology of photosynthesis in sunflower. J. Exp. Bot. 53, 1781-1791. doi: 10.1093/jxb/ erf021

Tezara, W., Mitchell, V. J., Driscoll, S. D., and Lawlor, D. W. (1999). Water stress inhibits plant photosynthesis by decreasing coupling factor and ATP. Nature 401, 914-917. doi: 10.1038/44842

Tosens, T., Niinemets, U., Vislap, V., Eichelmann, H., and Castro Díez, P. (2012). Developmental changes in mesophyll diffusion conductance and photosynthetic capacity under different light and water availabilities in Populus tremula: how structure constrains function. Plant Cell Environ. 35, 839-856. doi: $10.1111 / j .1365-3040.2011 .02457 . x$

Ubierna, N., Sun, W., Kramer, D. M., and Cousins, A. B. (2012). The efficiency of C4 photosynthesis under low light conditions in Zea mays, Miscanthus $x$ giganteus and Flaveria bidentis. Plant Cell Environ. 36, 365-381. doi: 10.1111/j. 1365-3040.2012.02579.x
Vapaavuori, E. (1986). Correlation of activity and amount of Ribulose 1,5bisphosphate Carboxylase with chloroplast stroma crystals in water-stressed willow leaves. J. Exp. Bot. 37, 89-98. doi: 10.1093/jxb/37.1.89

Verlag, F., Vu, J. C. V., Newman, Y. C., Allen, L. H., Gallo-meagher, M., and Zhang, M. (2002). Photosynthetic acclimation of young sweet orange trees to elevated growth CO2 and temperature. J. Plant Physiol. 159, 147-157. doi: 10.1078/0176-1617-00689

Vile, D., Pervent, M., Belluau, M., Vasseur, F., Bresson, J., Muller, B., et al. (2012). Arabidopsis growth under prolonged high temperature and water deficit: independent or interactive effects? Plant Cell Environ. 35, 702-718. doi: 10.1111/j.1365-3040.2011.02445.x

von Caemmerer, S. (2000). Biochemical Models of Leaf Photosynthesis. Collingwood: CSIRO, Collingwood.

von Caemmerer, S., and Evans, J. R. (2010). Enhancing C3 photosynthesis. Plant Physiol. 154, 589-592. doi: 10.1104/pp.110.160952

von Caemmerer, S., and Evans, J. R. (2015). Temperature responses of mesophyll conductance differ greatly between species. Plant Cell Environ. 38, 629-637. doi: $10.1111 /$ pce. 12449

von Caemmerer, S., and Furbank, R. T. (1999). "The modelling of C4 photosynthesis," in The Biology of C4 Photosynthesis, ed. R. Sage (New York, NY: Academic Press), 173-211.

von Caemmerer, S., and Furbank, R. T. (2016). Strategies for improving C4 photosynthesis. Curr. Opin. Plant Biol. 31, 125-134. doi: 10.1016/j.pbi.2016. 04.003

Walker, B., Ariza, L. S., Kaines, S., Badger, M. R., and Cousins, A. B. (2013). Temperature response of in vivo Rubisco kinetics and mesophyll conductance in Arabidopsis thaliana: comparisons to Nicotiana tabacum. Plant Cell Environ. 36, 2108-2119. doi: 10.1111/pce.12166

Way, D. A., and Yamori, W. (2014). Thermal acclimation of photosynthesis: on the importance of adjusting our definitions and accounting for thermal acclimation of respiration. Photosynth. Res. 119, 89-100. doi: 10.1007/s11120-0139873-7

Xiong, D., Liu, X., Liu, L., Douthe, C., Li, Y., Peng, S., et al. (2015). Rapid responses of mesophyll conductance to changes of $\mathrm{CO}_{2}$ concentration, temperature and irradiance are affected by $\mathrm{N}$ supplements in rice. Plant Cell Environ. 38, 2541-2550. doi: 10.1111/pce. 12558

Yamori, W., Hikosaka, K., and Way, D. A. (2014). Temperature response of photosynthesis in C3, C4, and CAM plants: temperature acclimation and temperature adaptation. Photosynth. Res. 119, 101-117. doi: 10.1007/s11120013-9874-6

Yamori, W., Noguchi, K., Kashino, Y., and Terashima, I. (2008). The role of electron transport in determining the temperature dependence of the photosynthetic rate in spinach leaves grown at contrasting temperatures. Plant Cell Physiol. 49, 583-591. doi: 10.1093/pcp/pcn030

Yamori, W., Suzuki, K., Noguchi, K., Nakai, M., and Terashima, I. (2006). Effects of Rubisco kinetics and Rubisco activation state on the temperature dependence of the photosynthetic rate in spinach leaves from contrasting growth temperatures. Plant Cell Environ. 29, 1659-1670. doi: 10.1111/j.1365-3040.2006.01550.x

Yamori, W., and von Caemmerer, S. (2009). Effect of Rubisco activase deficiency on the temperature response of $\mathrm{CO} 2$ assimilation rate and Rubisco activation state: insights from transgenic tobacco with reduced amounts of Rubisco activase. Plant Physiol. 151, 2073-2082. doi: 10.1104/pp.109.146514

Yin, X., van der Putten, P. E. L., Driever, S. M., and Struik, P. C. (2016). Temperature response of bundle-sheath conductance in maize leaves. J. Exp. Bot. 67, 2699-2714. doi: 10.1093/jxb/erw104

Zhang, N., Kallis, R., Ewy, R., and Portis, A. J. (2002). Light modulation of Rubisco in Arabidopsis requires a capacity for redox regulation of the larger Rubisco activase isoform. Proc. Natl. Acad. Sci. U.S.A. 99, 3330-3334. doi: 10.1073/pnas. 042529999

Zhang, N., and Portis, A. J. (1999). Mechanism of light regulation of Rubisco: a specific role for the larger Rubisco activase isoform involving reductive activation by thioredoxin-f. Proc. Natl. Acad. Sci. U.S.A. 96, 9438-9443. doi: $10.1073 /$ pnas.96.16.9438

Zhou, Y., Lam, H. M., and Zhang, J. (2007). Inhibition of photosynthesis and energy dissipation induced by water and high light stresses in rice. J. Exp. Bot. 58, 1207-1217. doi: 10.1093/jxb/erl291

Zhu, C., Ziska, L., Zhu, J., Zeng, Q., Xie, Z., Tang, H., et al. (2012). The temporal and species dynamics of photosynthetic acclimation in flag 
leaves of rice (Oryza sativa) and wheat (Triticum aestivum) under elevated carbon dioxide. Physiol. Plant. 145, 395-405. doi: 10.1111/j.1399-3054.2012. 01581.x

Conflict of Interest Statement: The authors declare that the research was conducted in the absence of any commercial or financial relationships that could be construed as a potential conflict of interest.
Copyright $\odot 2017$ Perdomo, Capó-Bauçà, Carmo-Silva and Galmés. This is an openaccess article distributed under the terms of the Creative Commons Attribution License (CC BY). The use, distribution or reproduction in other forums is permitted, provided the original author(s) or licensor are credited and that the original publication in this journal is cited, in accordance with accepted academic practice. No use, distribution or reproduction is permitted which does not comply with these terms. 